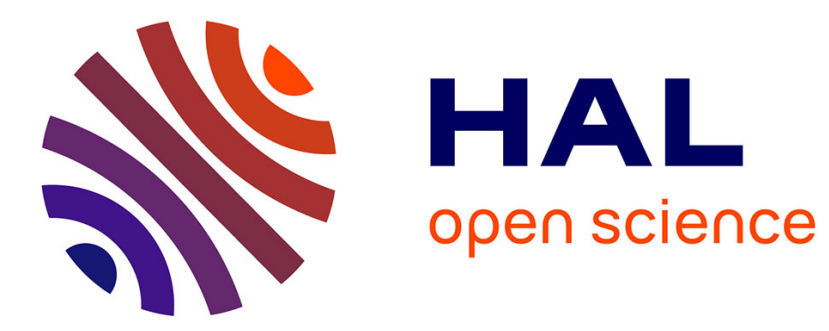

\title{
Linear porphyrin dimers with fluorenyl arms linked by an ethynyl bridge
}

\author{
Areej Merhi, Samuel Drouet, Nicolas Kerisit, Christine Paul-Roth
}

\section{To cite this version:}

Areej Merhi, Samuel Drouet, Nicolas Kerisit, Christine Paul-Roth. Linear porphyrin dimers with fluorenyl arms linked by an ethynyl bridge. Tetrahedron, 2013, 69 (34), pp.7112-7124. 10.1016/j.tet.2013.06.019 . hal-00840579

\section{HAL Id: hal-00840579}

\section{https://hal-univ-rennes1.archives-ouvertes.fr/hal-00840579}

Submitted on 8 Jul 2013

HAL is a multi-disciplinary open access archive for the deposit and dissemination of scientific research documents, whether they are published or not. The documents may come from teaching and research institutions in France or abroad, or from public or private research centers.
L'archive ouverte pluridisciplinaire HAL, est destinée au dépôt et à la diffusion de documents scientifiques de niveau recherche, publiés ou non, émanant des établissements d'enseignement et de recherche français ou étrangers, des laboratoires publics ou privés. 


\section{Graphical Abstract}

\section{Linear Porphyrin Dimers with Fluorenyl Arms linked by an Ethynyl bridge}

Areej Merhi, ${ }^{\mathrm{a}, \mathrm{b}}$ Samuel Drouet, ${ }^{\mathrm{a}}$ Nicolas Kerisit, ${ }^{\mathrm{a}}$ Christine O. Paul-Roth* ${ }^{\mathrm{a}, \mathrm{b}}$

${ }^{a}$ Institut de Sciences Chimiques de Rennes, ISCR-UMR CNRS 6226,

Université de Rennes 1, Campus de Beaulieu, 35042 Rennes Cedex, France.

${ }^{\mathrm{b}}$ Institut National des Sciences Appliquées, INSA-ISCR, 35043 Rennes Cedex, France.

*Corresponding author. Fax: 02232356 37; Tel.: 0223236372

E-mail: christine.paul@univ-rennes1.frorchristine.paul@insa-rennes.fr

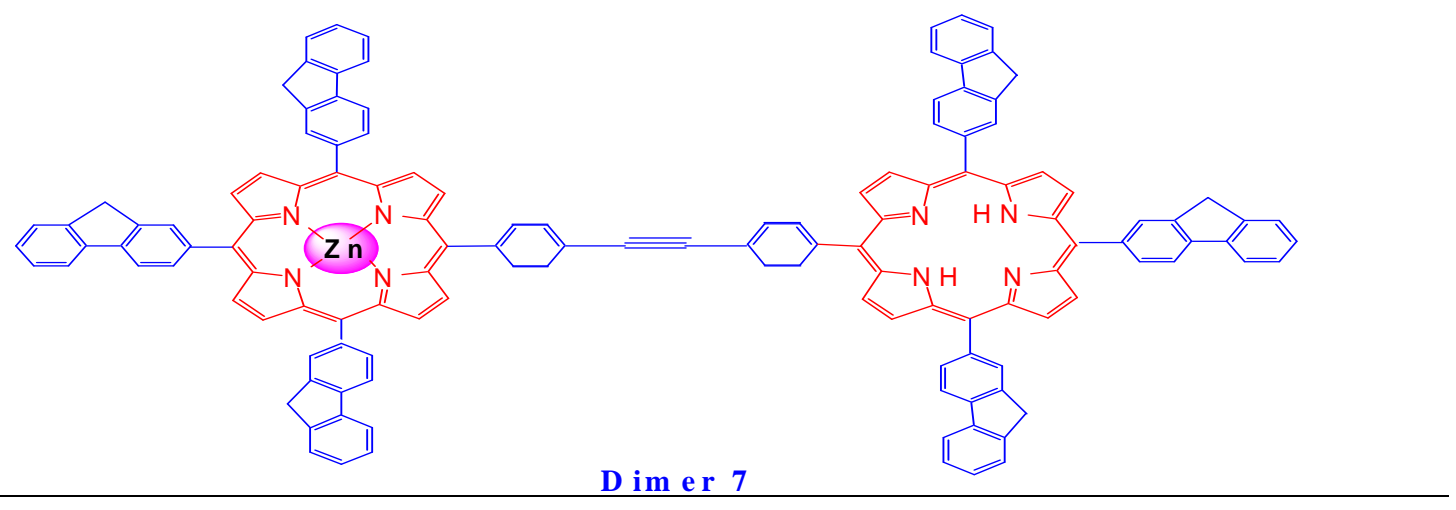




\title{
Linear Porphyrin Dimers with Fluorenyl Arms linked by an Ethynyl bridge
}

Areej Merhi, ${ }^{a, b}$ Samuel Drouet, ${ }^{a}$ Nicolas Kerisit, ${ }^{a}$

Christine O. Paul-Roth* ${ }^{\text {a,b }}$

a Institut de Sciences Chimiques de Rennes, ISCR-UMR CNRS 6226, Université de Rennes 1, Campus de Beaulieu, 35042 Rennes Cedex, France.

${ }^{\mathrm{b}}$ Institut National des Sciences Appliquées, INSA-ISCR, 35043 Rennes Cedex, France.

*Corresponding author. Fax: 02232356 37; Tel.: 0223236372

e-mail:christine.paul@univ-rennes1.fror christine.paul@insa-rennes.fr

\begin{abstract}
A series of porphyrin monomers bearing fluorenyl donor groups is presented; successively, compounds 10, 11, 12 and 13 bearing three fluorenyl groups. Starting from these building blocks, the synthesis of new porphyrin ethynyl - linked dimers $\mathbf{7}$ and $\mathbf{8}$, bearing in totally six peripheral fluorenyl arms is attempted. Dimers are obtained by coupling two porphyrin monomers, using a palladium catalyst, by a rigid bridge. Luminescence studies of new dimers $\mathbf{7}$ and $\mathbf{8}$ are presented. We can then compare the detailed luminescence properties of these dimers with former porphyrin monomer possessing four fluorenyl arms TFP (2), which is the precursor model of this work, to porphyrin dendrimers bearing various numbers of fluorenyl arms (3 and 4) and finally to corresponding supramolecular assemblies (5 and 6).
\end{abstract}

Keywords : Porphyrins; Fluorene; Dimer; Luminescence; Quantum Yield

\section{Introduction}

Assemblies of porphyrins have shown interesting properties for the fabrication of electronic devices, optical and for the conversion of solar energy. For efficient solar energy harvesting, several chromophores are needed in order to collect light from the entire solar spectrum. ${ }^{1}$ In this connection, the photosynthetic light-harvesting systems (I and II) consist of well-organized porphyrin antennas in sophisticated three-dimensional structures. ${ }^{2}$ As in 
nature, construction of multi-chromophore systems is important to ensure maximum use of solar energy. Thus, the ability to design and construct molecular architectures in which the energy flow can be controlled constitutes a great challenge. One approach is to use porphyrins as building blocks and to assemble them by different coupling methods. There are many ways to link porphyrins together, for example, for one of the first assemblies; the ester bond was used in 1976 by Anton $^{3}$ to synthesis diporphyrins and triporphyrins. These compounds were studied for the energy and electrons transfer in biological processes. In 1983, Milgrom published the synthesis of a broad assembly of porphyrins, linked by ether bond, to study the properties of light collection. ${ }^{4}$ Many assemblies in which the porphyrins are directly connected by a single bond, usually between the meso positions, have been prepared by Smith's group, these systems allow electronic interactions between coupled porphyrins. ${ }^{5}$ Therien et al. published the synthesis of porphyrins dimer linked in meso position by a triple bond as a model for light collecting antenna. ${ }^{6}$ Later, the synthesis of dimers and trimers linked by a ethynyl bond in different positions like the meso-meso, meso- $\beta$ and $\beta-\beta$, was proposed to study the influence on the properties of absorption and emission. ${ }^{7}$ Lindsey's research group has developed methods for the preparation of a wide variety of assemblies of porphyrins linked by alkyne-aryl bond; they studied their potential as light collector. This approach was used to form linear porphyrin like dimers and trimers, ${ }^{8,9}$ we will now consider this type of linear rigid ethynyl bridge.

On our side, we have previously reported the synthesis of porphyrin possessing four fluorenyl arms directly connected at the meso-positions (TFP, compound 2). ${ }^{10-13}$ More recently, a complete family of relevant porphyrins was studied in collaboration with Williams. ${ }^{14}$ Surprisingly, TFP exhibited a remarkably high quantum yield (24\%), compared to the reference TPP, demonstrating the capacity of the fluorenyl units to enhance quantum yields. We next tested the corresponding platinum(II) complex in the fabrication of red Organic Light Emitting Diodes (OLEDs) obtained by vapour diffusion deposition ${ }^{15,16}$ or spin coating. ${ }^{17}$ Then, to exploite this efficiency, a series of porphyrin dendrimers (generations G1 and $G_{2}$ ) bearing these fluorenyl dendrons, was prepared, namely: 3 and 4 (Fig. 1). However, the synthesis of a higher generation porphyrin $\left(\mathrm{G}_{3}\right)$ failed, most likely the so called "starburst limit effect" was reached. ${ }^{18}$ Also, supramolecular assemblies $\mathbf{5}$ and $\mathbf{6}$, using these efficient building blocks have been prepared and studied by our group (Fig. 1). ${ }^{17}$ 

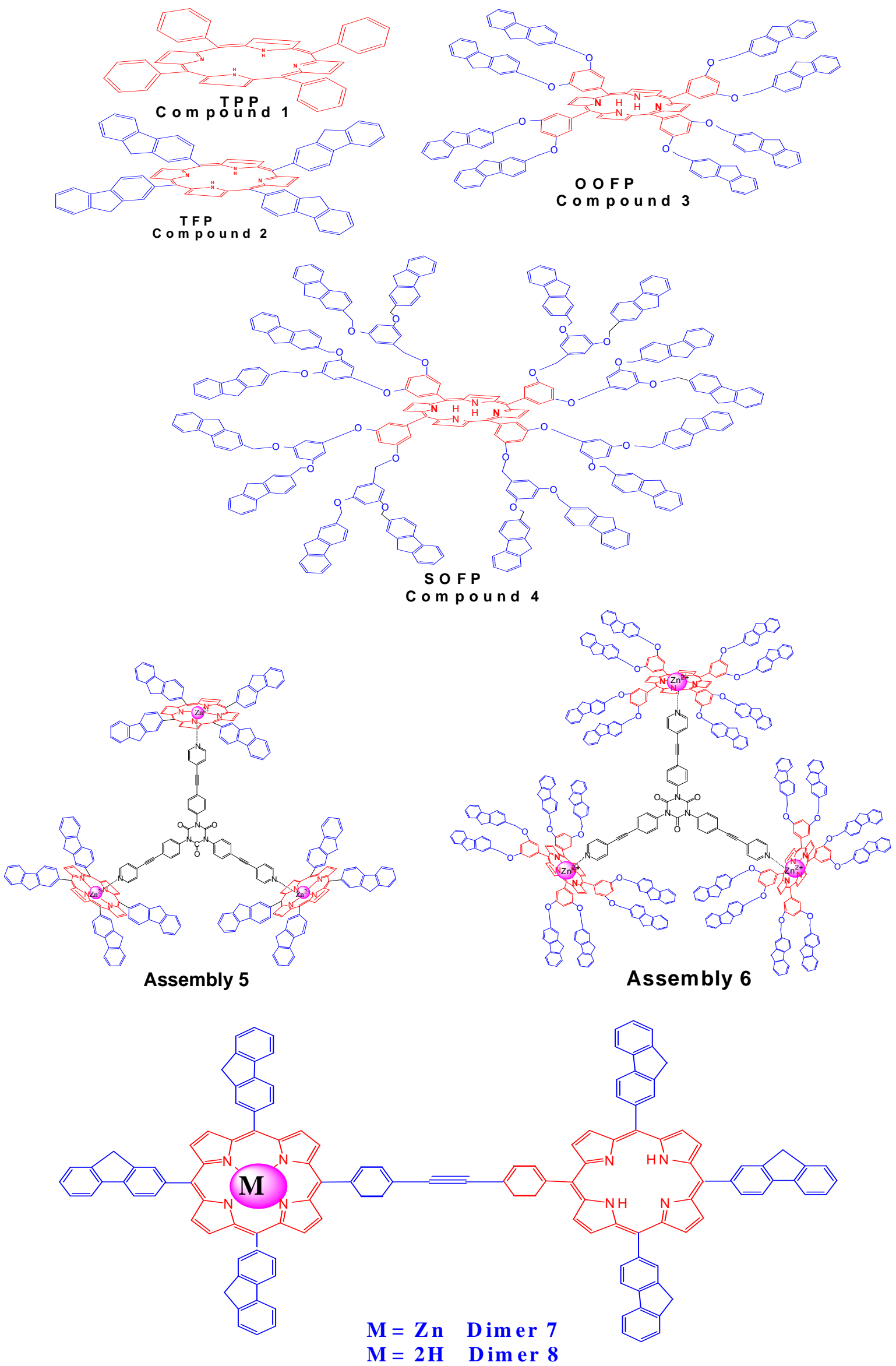

Figure 1: $\quad$ Compounds $1,2,3,4,5,6,7$ and 8 
Another way to exploit highly efficient fluorenyl-based antennae with systems like TFP will be proposed in this report. After consideration of all these examples of assemblies, and knowing the capacity of fluorenyl arms to absorb light, the idea is to synthesize dimers of porphyrins as a model for the effect of light collecting antenna, substituted by six fluorenyls units in the meso position. In addition, we have seen that when the fluorenyl units were directly connected at the meso position like in TFP, there was a high fluorescence quantum yield. The preparation of a new assemblies of fluorenyl-porphyrins linked by alkyne-aryl bond $^{8,9}$ will be considered and by this approach, we will form linear porphyrin dimers.

The bond will be formed by coupling a porphyrin with an iodo group and another with a terminal alkyne function, catalyzed by a palladium complex, studied in different conditions. However, in this respect, the synthesis of new monomers is required. To this aim, new building blocks with three peripheral fluorenyl groups and one anchoring point are described $(10,11,12$ and 13).

Photophysical results concerning new linear porphyrin dimers free and zinc complex are reported and compared to previous data for monomer $\mathbf{T F P},{ }^{19}$ secondly to the porphyrin dendrimers bearing fluorenyl dendrons, namely: 3 and $\mathbf{4}$ (generation $\mathrm{G}_{1}$ and $\mathrm{G}_{2}$ ) $^{18,20,21}$ and finally to the corresponding supramolecular assemblies using these efficient building blocks $\mathbf{5}$ and 6. $^{17}$

\section{Results and discussion}

\subsection{Synthesis}

2.1.1. Objectives - The aim of this work consist of the synthesis of porphyrin dimer starting from two types of porphyrins: one substituted at three positions by meso fluorenyl units and an acetylenic group on purpose to future ethynyl-link by a phenyl-C $\equiv \mathrm{C}$-phenyl bridge, another, with also three fluorenyl units in the meso positions, with one activable iodo group to link with a rigid bridge. The synthesis strategy is based on the coupling of two $\mathrm{A}_{3} \mathrm{~B}$ porphyrins; one metallized, and another free, for an easier separation. This biporphyrinconnection is made by a Sonogashira coupling, under conditions optimized by Lindsey. ${ }^{8,9}$

First, we will describe the synthesis of prepared aldehyde 9 and then in more details, the synthesis of the new intermediate porphyrins 10,11, 12 and 13, possessing one anchoring point. In a second time, the previous intermediate porphyrins $\mathbf{1 2}$ and $\mathbf{1 3}$ are connected to obtain the dimer zinc complex porphyrins $\mathbf{7}$ and by dematallation: to obtain free base dimer $\mathbf{8}$. 
Preliminary photophysical results are reported; in this case, six efficient antennea are connected by direct meso connection to the porphyrin macrocycles.

It should be noted that in the conditions used, the non-substituted fluorenyl arm is stable but alkyl chains have often been introduced on the position-9 of the fluorenyl units to increase their solubility. ${ }^{22}$

2.1.2. Synthesis of 4-((trimethylsilyl) ethynyl) benzaldehyde 9. This synthesis is done in one step by Sonogashira coupling. In more details, the aldehyde 9 is prepared by coupling between 4-bromobenzaldehyde and (trimethylsilyl) ethynyl in the presence of a palladium catalyst, a cocatalyst (copper/iodide), and a base (triethylamine) in THF. ${ }^{23}$ The aldehyde 9 is obtained as a white powder with a yield of $92 \%$.

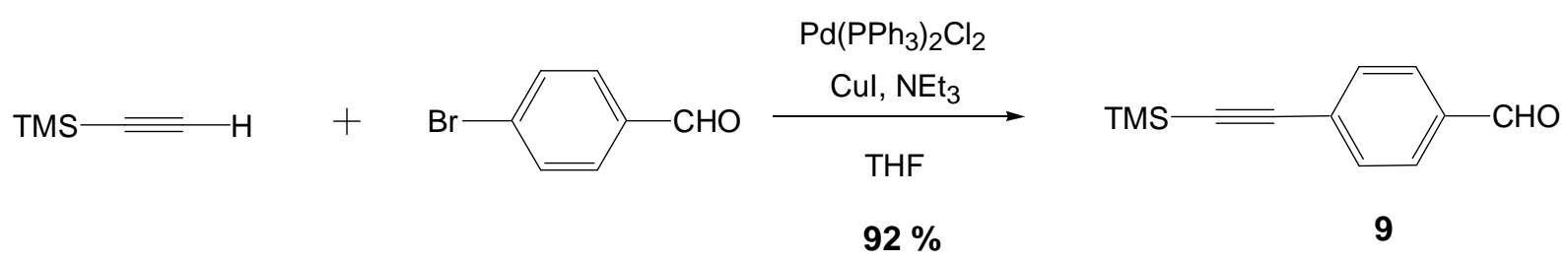

Scheme 1: $\quad$ Synthesis of compound 9 (4 - ((trimethylsilyl)ethynyl) benzaldehyde)

\subsubsection{Synthesis and characterization of porphyrin 10, possessing three fluorenyl arms.} The protected free-base porphyrin $\mathrm{A}_{3} \mathrm{~B}(\mathbf{1 0})$, was prepared from two aldehydes: the fluorenylcarbaldehyde (commercial) and previous prepared; 4-((trimethylsilyl) ethynyl) benzaldehyde $\mathbf{9}$. The synthesis of porphyrin $\mathbf{1 0}$ is made by the method of Lindsey: it consists of mixed condensation between two different aldehydes and pyrrole (Scheme 2). Three equivalents of fluorenylcarbaldehyde and one equivalent of benzaldehyde 9, prepared in advance, are reacted with four equivalents of pyrrole. The reaction takes place in chloroform, at room temperature, catalyzed by the Lewis acid $\mathrm{BF}_{3} . \mathrm{OEt}_{2}$. After three hours of reaction, adding three equivalents of $\mathrm{p}$-chloranil in order to oxidize the porphyrinogen formed, the reaction mixture is refluxed for one hour. After neutralization of the acid catalyst with triethylamine, the solvent is evaporated. Porphyrin $\mathbf{1 0}$ is isolated as a purple solid from other reaction products (polymers as well as mono fluorenyl, di fluorenyl, etc...) by chromatography on silica gel with a yield of $15 \%$, and was fully characterized. 


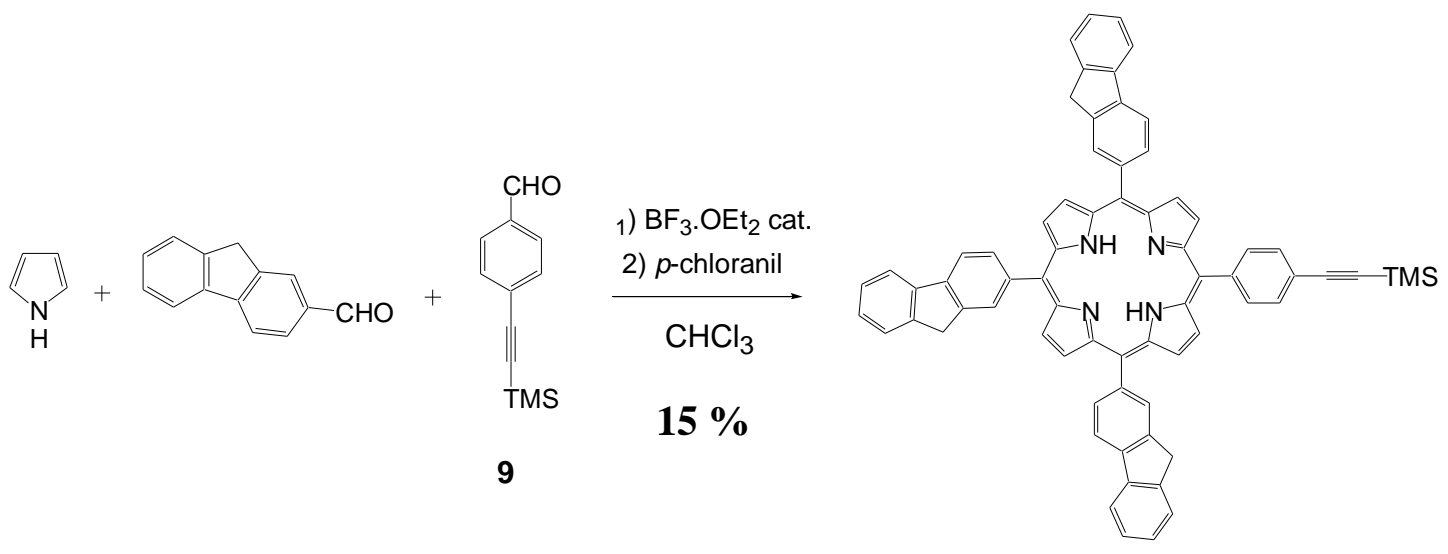

10

Scheme 2: $\quad$ Synthesis of porphyrin 10

2.1.4. Preparation and characterization of deprotected porphyrin 11, possessing three fluorenyl arms - The porphyrin $\mathbf{1 0}$ is then basified to give the free-base porphyrin 11: with the deprotected acetylenic function (Scheme 3). This deprotection step of $\mathbf{1 0}$ involves the action of a base: potassium carbonate in a mixture of solvent (DCM /methanol) at room temperature. Deprotected porphyrin 11 was obtained as a dark red-violet powder with a yield of $98 \%$, and was fully characterized; the hydrogen and carbon atom-labeling Scheme is shown in Figure 2.



10

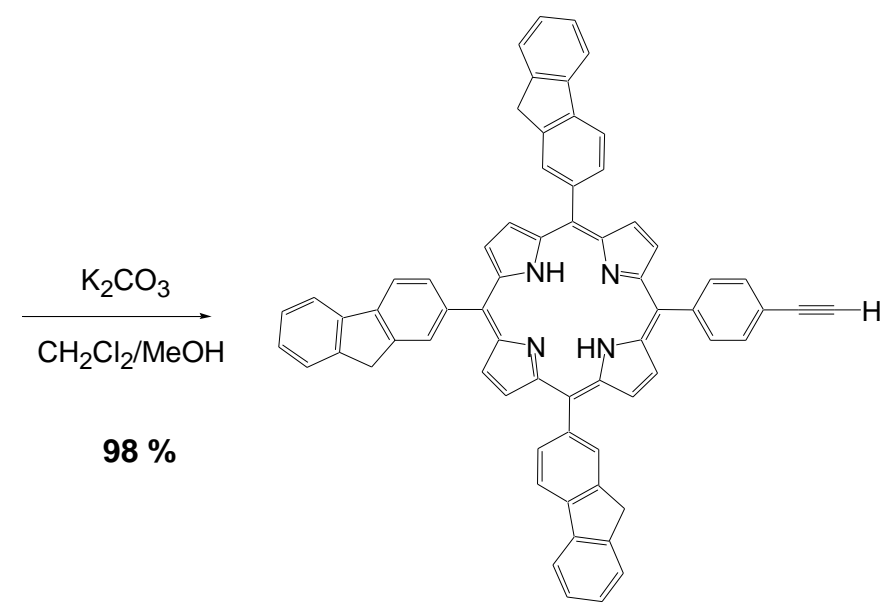

11

Scheme 3: $\quad$ Synthesis of porphyrin 11

2.1.5. Preparation and characterization of the zinc porphyrin complex 12 - The free base porphyrin 11 is then metallated in a (DCM /methanol) mixture at R.T., in the presence of five equivalents of zinc acetate, $\mathrm{Zn}\left(\mathrm{CH}_{3} \mathrm{CO}_{2}\right)_{2} \cdot 2 \mathrm{H}_{2} \mathrm{O}$ under inert atmosphere, to give the zinc porphyrin complex 12 (Scheme 4). The reaction progress was monitored by UV-visible spectroscopy or by TLC, spotting directly from the organic layer. The zinc complex $\mathbf{1 2}$ is 
obtained as a dark red powder with a yield 97\%. New zinc complex porphyrin 12 was fully characterized; the hydrogen and carbon atom-labeling Scheme is shown in Figure 2.

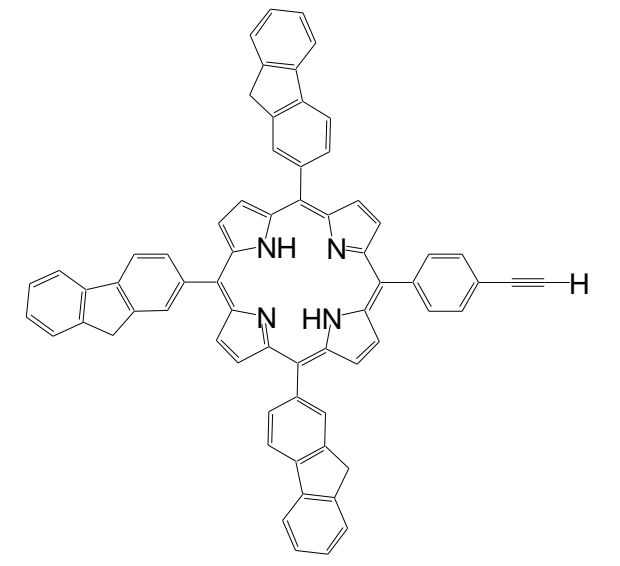

11

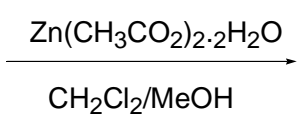

$97 \%$

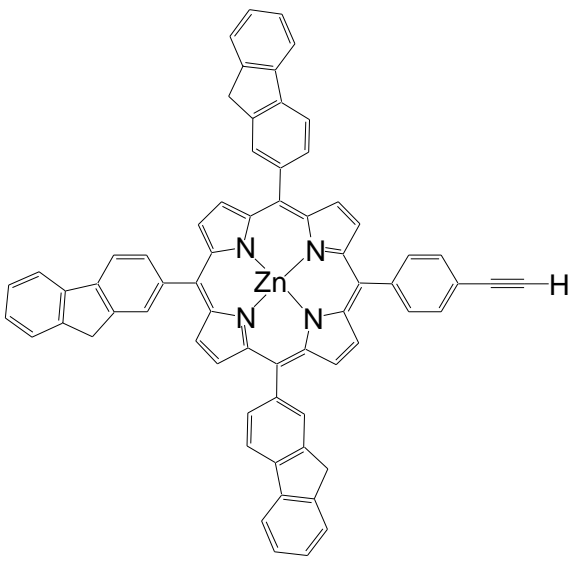

12

Scheme 4: $\quad$ Synthesis of zinc porphyrin complex 12

2.1.6. Synthesis and characterization of porphyrin-free base 13, possessing three fluorenyl arms. The second type porphyrin is prepared in one step, according to the method of Lindsey and consists of mixed condensation between two aldehydes and pyrrole (Scheme 5). Three equivalents of fluorenylcarbaldehyde and one equivalents of 4-iodobenzaldehyde for four equivalents of pyrrole are reacted. The reaction takes place in chloroform at room temperature, catalyzed by the Lewis acid: $\mathrm{BF}_{3} \cdot \mathrm{OEt}_{2}$. After three hours of reaction, three equivalents of oxidant; p-chloranil are added and the reaction mixture was refluxed for one hour. After neutralization of the acid catalyst by triethylamine, the solvent is evaporated. Porphyrin $\mathbf{1 3}$ is isolated as a violet powder, from other reaction products (polymers as well as mono fluorenyl, tri fluorenyl, etc.) by several successive chromatographies on silica gel, with a yield of $8 \%$. New intermediate porphyrin 13 was fully characterized; the hydrogen and carbon atom-labeling Scheme is shown in Figure 2. 


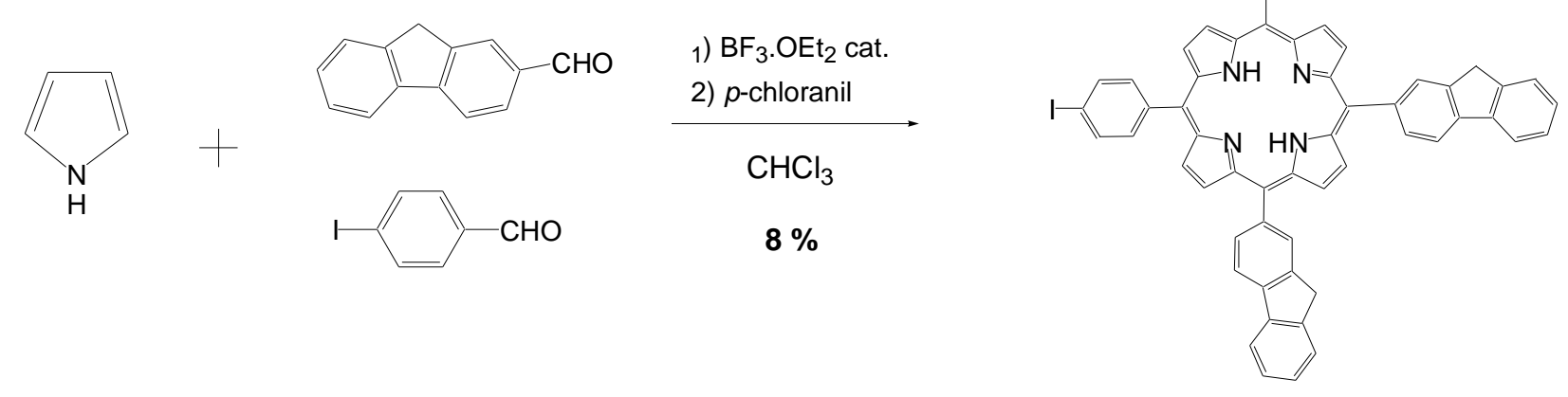

Scheme 5: $\quad$ Synthesis of iodo porphyrin-intermediate $\mathbf{1 3}$

13

2.1.7. Synthesis and characterization of the dimer possessing six fluorenyl arms 7 The dimer 7 consists of a covalently linked assembly of two porphyrins, one metallated by zinc: 12 and free-base 13, separated by a rigid phenyl-phenyl triple bond bridge. This new dimer possesses in totally six fluorenyl groups directly connected in meso position, this should exalt the luminescence of the compound.

First, the reaction is performed by adding a slightly excess of zinc complex porphyrin 12 to one equivalent of free base iodo-porphyrin 13 in a mixture of (THF/triethylamine) (5/1) in the presence of $\mathrm{Pd}(0)$ catalyst and a large excess of triphenylarsine $\left(\mathrm{AsPh}_{3}\right)$ as ligand (Scheme 6a). In these conditions the yield is very low (5\%) and it was difficult to isolate dimer 7.

In more details, to a solution of a slightly excess of zinc complex porphyrin 12, and one equivalent of $13,0.3$ eq of the $\operatorname{Pd}(0)$ catalyst is added: $\operatorname{Pd}_{2}($ dibenzylidene acetone $)_{3} . \mathrm{CHCl}_{3}\left(\mathrm{Pd}_{2}(\mathrm{dba})_{3}\right)$. Then, finally, 2.4 equivalent of $\mathrm{AsPh}_{3}$ in freshly distillate THF and triethylamine (5/1 mixture), were added. This solution was stirred for 72 hours at $35{ }^{\circ} \mathrm{C}$ under argon. Then, the reaction mixture was cooled at room temperature, filtered and evaporated to dryness. These conditions optimized by Lindsey ${ }^{8,9}$ are preferred to standard conditions for Sonogashira coupling involving copper iodide, in order to avoid any risk of porphyrin copper formation. The residue was purified by two successive column chromatographies on silica gel, using (DCM/heptane) as an eluent and is purified by precipitation (heptane), affording the desired product 7, as a dark red powder with a yield of 5\%. In these conditions two by-products were isolated: compounds $\mathbf{1 4}$ and $\mathbf{1 5}$ (Scheme 6b). 
To avoid formation of former by-products and to optimize the yield, a different ligand as $\mathrm{AsPh}_{3}$ for the palladium catalyst: tri(o-tolyl)phosphine $\left(\mathrm{P}(\mathrm{o}-\mathrm{tol})_{3}\right)$ was tried. In these different conditions, a reasonable yield could be reached.

In more details, the reaction is now performed by adding one equivalent of zinc complex porphyrin 12 and one equivalent of free base iodo-porphyrin 13 in a mixture of (toluene/triethylamine) (5/1) in the presence of 0.3 eq of $\mathrm{Pd}(0)$ catalyst and an excess of $\mathrm{P}(\mathrm{o}-$ tol $)_{3}$ as ligand (Scheme 6a). The reaction mixture was stirred for 24 hours at $35^{\circ} \mathrm{C}$ under argon. In these conditions, the yield is acceptable (25\%) and it is possible, after 2 chromatographies and precipitation in heptane to isolate dimer 7 pure, as a dark red powder. The connection was confirmed by matrix-assisted laser desorption ionization time-of-flight mass spectrometry (MALDI-TOF MS) and UV-Visible spectrometry. This new compound 7 is very soluble in most organic solvents and can be purified by precipitation $\left(\operatorname{Et}_{2} \mathrm{O}\right.$, heptane). Compound 7 was fully characterized by usual solution spectroscopies (NMR, mass spectrometry) and microanalysis. For clarity by NMR, the hydrogen and carbon atom-labeling scheme is shown in Figure 3.
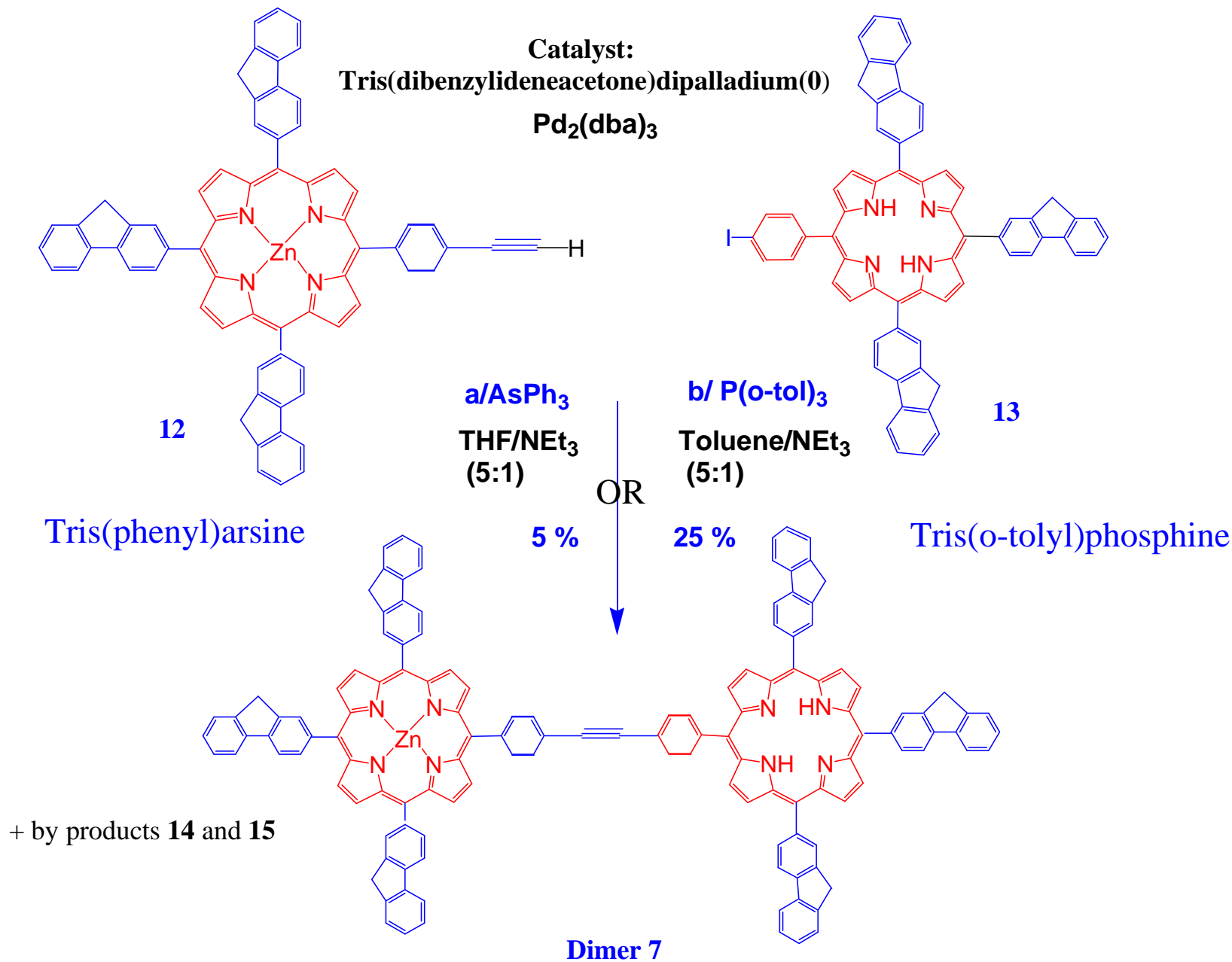

a/ 


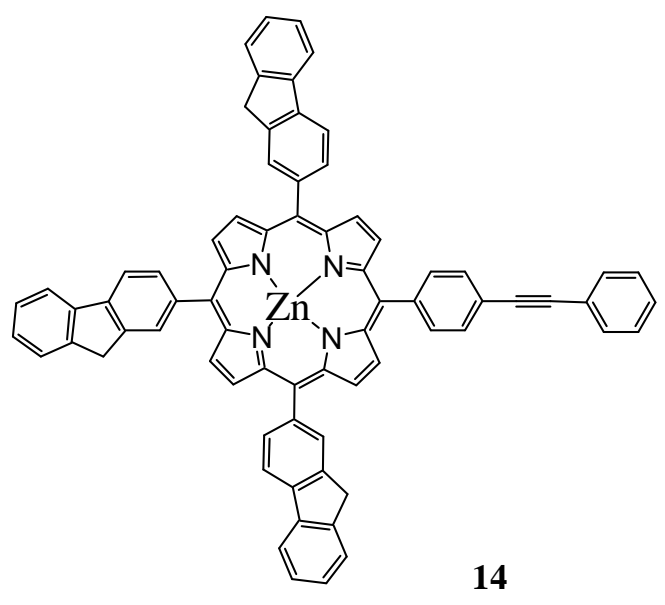

b/

Scheme 6:

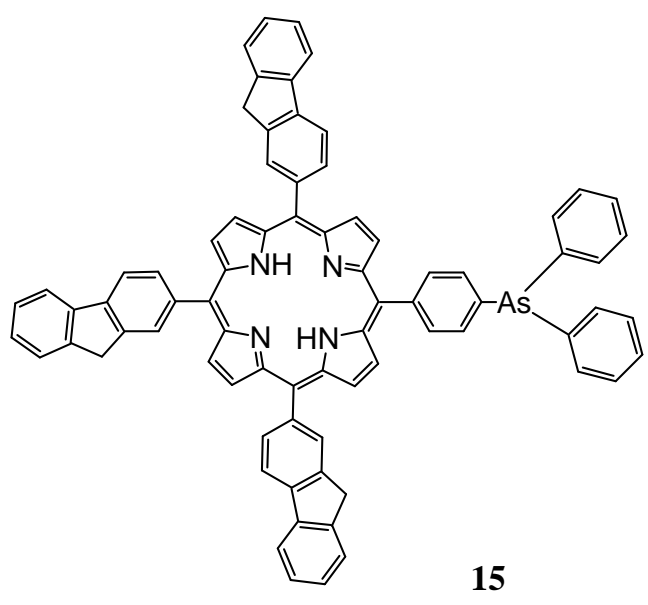

15

2.1.8. Synthesis and characterization of the free dimer possessing six fluorenyl arms 8 - This new free dimer $\mathbf{8}$ was obtained from the mono zinc complex $\mathbf{7}$ by acidic treatments with a Bronsted acid, like trifluoro-acetic acid (TFA), the dark red DCM solution turns immediately green. The reaction mixture was stirred and controlled by UV-Vis spectrometry to be sure the entire zinc complex is eliminated, to obtain the totally free and protonated porphyrin dimer. Finally, sodium carbonate was added to neutralize acid and to get a red solution, to obtain the free, not protonated porphyrin dimer $\mathbf{8}$. Then, the residue was purified by column chromatography on silica gel using DCM to obtain neutral $\mathbf{8}$. This free dimer $\mathbf{8}$ was characterized by NMR, UV-Vis and mass spectrometry.

\subsection{NMR studies}

The ${ }^{1} \mathbf{H}$ NMR signals obtained in deuterated chloroform for porphyrins 10, 11, 12, 13 and finally $\mathbf{7}$ and $\mathbf{8}$, were carried out at room temperature, are fine and well resolved.

${ }^{1} \boldsymbol{H}$ NMR characterization of compound $\mathbf{1 0}$ and $\mathbf{1 1}$ - At high field, around -3 ppm, we observe the two protons carried by the nitrogen atoms in the heart of the porphyrin, this observed shift is due to be in the shielding cone of the porphyrin macrocycle. At $4.2 \mathrm{ppm}$, are the $\mathrm{CH}_{2}$ protons of the three fluorenyl groups. In the region between 7.5 and $8.5 \mathrm{ppm}$ resonate the aromatic protons (fluorenyl and phenyl). Concerning the meso substituents of the porphyrin: we can notice that all the seven protons on the three fluorenyl arms are equivalent, and in 
expected position: $8.38(\mathrm{~s}, 3 \mathrm{H}) ; 8.25(\mathrm{~d}, 3 \mathrm{H}) ; 8.17(\mathrm{~d}, 3 \mathrm{H}) ; 8.06(\mathrm{~d}, 3 \mathrm{H}) ; 7.70(\mathrm{~d}, 3 \mathrm{H}), 7.52(\mathrm{~m}$, $3 \mathrm{H})$ and $7.44(\mathrm{~m}, 3 \mathrm{H})$. At low field; around $9 \mathrm{ppm}$, there are three signals, a singlet integrating for four protons and an $\mathrm{AB}$ system; two doublets, for two protons each, they are all assigned to the protons pyrrole- $\beta$ which, being located outside the shielding cone, are highly deshielded. For these two intermediate compounds $\mathbf{1 0}$ and 11, there is only a clear difference for the protons of the methyl trimethylsilyl group $(0.4 \mathrm{ppm})$ and for the acetylenic function at 3.3 ppm. The other proton signals are quiet similar.

${ }^{1} \boldsymbol{H}$ NMR characterization of compound 12 - For this zinc complex and for the precursor 11, there is only a clear difference for the protons carried by the nitrogen atoms in the heart of the porphyrin; around $-3 \mathrm{ppm}$, these protons are not observed for the zinc complex 12. The other proton signals are quiet similar.

${ }^{1} \boldsymbol{H}$ NMR characterization of compound $\mathbf{1 3}$ is similar to free porphyrins $\mathbf{1 0}$ and $\mathbf{1 1 .}$
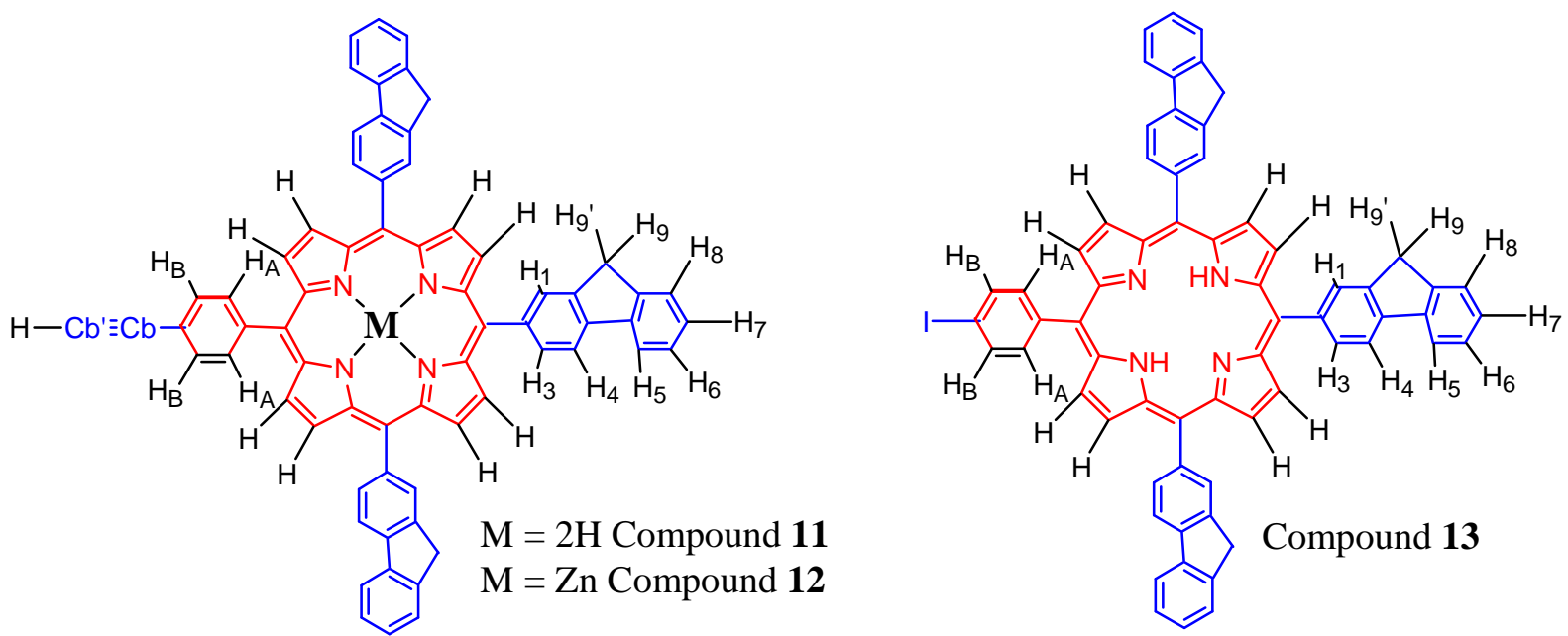

Figure 2: Hydrogen and carbon atom-labeling for porphyrins 11, 12 and for iodo porphyrin-intermediate 13

In Figure 4, we can observe the ${ }^{1} \mathrm{H}$ NMR studies (in $\mathrm{CDCl}_{3}$ ) of zinc complex 12 (on the top), in comparison to free base $\mathbf{1 3}$ possessing a peripheral iodo group showing the shift for the $\beta$ pyrrolic protons as indicated by the arrows. In this region, in both cases a singulet (integrating for $4 \mathrm{H}$ ) at 9.02 and $8.92 \mathrm{ppm}$ respectively, and an $\mathrm{AB}$ system (integrating for $4 \mathrm{H}$ ) are obtained. A small difference in shift is also observed for the four protons $\left(\mathrm{H}_{\mathrm{A}}\right.$, and $\left.\mathrm{H}_{\mathrm{B}}{ }^{\prime}\right)$ in the phenyl group; two doublets are observed, for zinc complex 12: $\delta=8.17 ; 7.89 \mathrm{ppm}$ and for the corresponding free base-iodo 13 , at $\delta=8.15 ; 7.96 \mathrm{ppm}$. The other proton signals are quiet similar and we can notice that all the seven peripheral protons on the three fluorenyl arms are equivalent for 12 and 13, and in expected positions : $8.4\left(\mathrm{H}_{1}\right), 8.3\left(\mathrm{H}_{4}\right), 8.1\left(\mathrm{H}_{3}\right), 8.0\left(\mathrm{H}_{5}\right), 7.7$ 
$\left(\mathrm{H}_{8}\right), 7.5\left(\mathrm{H}_{6}\right), 7.4\left(\mathrm{H}_{7}\right)$. Concerning the $\mathrm{CH}_{2}$ group of the fluorenyl $\left(\mathrm{H}_{9}\right.$ and $\mathrm{H}_{9}$ ): they are equivalent and in both monomers, we observe $\delta=4.20 \mathrm{ppm}$.

${ }^{1} \boldsymbol{H}$ NMR characterization of dimer compound 7 - One can note on Figure 4, the disappearance of the singlet corresponding to the acetylenic proton at $3.30 \mathrm{ppm}$ of the precursor zinc porphyrin complex 12. For 7, at high field, we could not observe the 2 protons carried by the nitrogen atoms of the porphyrin-free base in the dimer. At $4.2 \mathrm{ppm}$, there is a singlet for the 12 protons of the $\mathrm{CH}_{2}$ protons of the 6 fluorenyl groups. In the region between 7.5 and $8.5 \mathrm{ppm}$ resonate the aromatic protons (fluorenyl and phenyl), meso substituents of the porphyrin: we can notice that all the seven protons on the six fluorenyl arms are approximately equivalent. They are in expected positions in comparison to the monomers: $8.42(\mathrm{~s}, 6 \mathrm{H}) ; 8.29(\mathrm{~m}, 6 \mathrm{H}) ; 8.18(\mathrm{~m}, 6 \mathrm{H}) ; 8.06(\mathrm{~d}, 6 \mathrm{H}) ; 7.71(\mathrm{~d}, 6 \mathrm{H}) ; 7.54(\mathrm{t}, 6 \mathrm{H})$ and $7.43(\mathrm{t}$, $6 \mathrm{H})$. Around $9 \mathrm{ppm}$, there are five signals assigned to the protons pyrrole- $\beta$ : $9.09(\mathrm{~s}, 4 \mathrm{H})$, $9.07(\mathrm{~d}, 2 \mathrm{H}), 9.05(\mathrm{~s}, 4 \mathrm{H}), 9.04(\mathrm{~s}, 4 \mathrm{H}), 9.02(\mathrm{~d}, 2 \mathrm{H})$. Three of these signals are singulet integrating for four protons each and two signals are an AB system integrating in totally for four protons, due to the symmetry of this molecule.

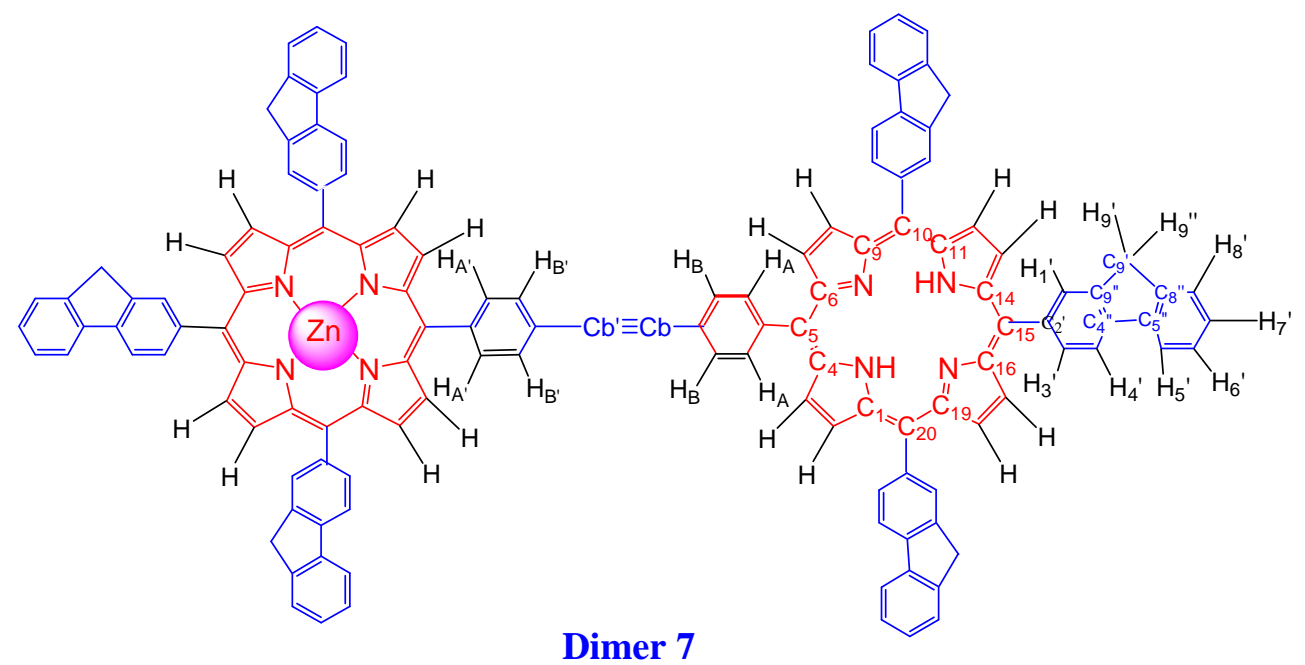

Figure 3: $\quad$ Hydrogen and carbon atom-labeling for new Dimer 7

${ }^{1} \boldsymbol{H}$ NMR characterization of free dimer compound $\boldsymbol{8}$ - Now at high field, we could observe the 4 protons carried by the nitrogen atoms of the two porphyrin-free bases in the dimer as a singulet at -2.70 . At $4.22 \mathrm{ppm}$, there is a singlet for the 12 protons of the $\mathrm{CH}_{2}$ protons of the 6 fluorenyl groups. As before, in the region between 7.4 and $8.9 \mathrm{ppm}$ resonate the aromatic protons (fluorenyl and phenyl) meso substituents of the porphyrin: we can notice that all the seven protons on the six fluorenyl arms are equivalent, and in expected positions in comparison to the monomers: $8.32(\mathrm{~s}, 6 \mathrm{H}) ; 8.18(\mathrm{~m}, 6 \mathrm{H}) ; 8.08(\mathrm{~m}, 6 \mathrm{H}) ; 7.98(\mathrm{~d}, 6 \mathrm{H}) ; 7.68(\mathrm{~d}$, 
$6 \mathrm{H}) ; 7.52(\mathrm{t}, 6 \mathrm{H})$ and $7.43(\mathrm{t}, 6 \mathrm{H})$. Around $8.9 \mathrm{ppm}$, there is a large signal for the 16 protons pyrrole- $\beta$.
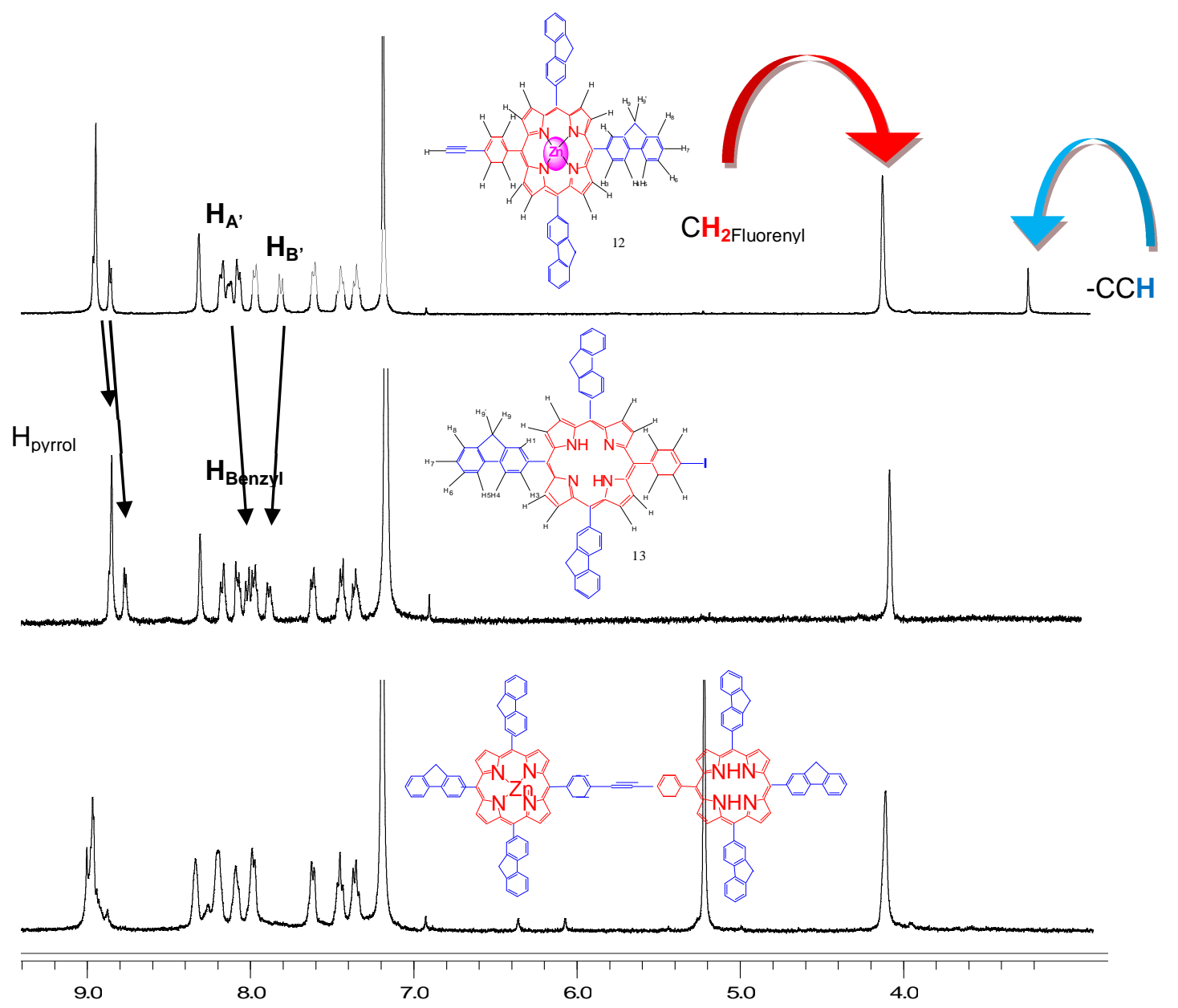

Figure 4: $\quad{ }^{1} \mathrm{H}-\mathrm{NMR}$ studies (in $\mathrm{CDCl}_{3}$ ) of Dimer 7 (with a $\mathrm{CH}_{2} \mathrm{Cl}_{2}$ pic), in comparison to zinc porphyrin complex 12 (on the top) and for iodo porphyrin-intermediate $\mathbf{1 3}$ showing the shift as indicated by the arrows.

\subsection{Photophysical properties}

2.3.1 Electronic spectra - The recording of the UV-visible absorption spectra of the porphyrins 10, 11, 12, 13 and finally 7,8 , was carried out at room temperature in DCM. For these compounds, measurements at different concentrations were performed; a more concentrated solution is used to display the $\mathrm{Q}$ bands and a less concentrated to the Soret band of porphyrin. The UV-visible spectra of free porphyrin 10, 11 and 13 exhibit an intense Soret band with a maximum absorption similar around $424 \mathrm{~nm}$ and four Q bands characteristic of a porphyrin free base which are located at 519, 555, and 593 and at $649 \mathrm{~nm}$. In addition, there is a wide band around $275 \mathrm{~nm}$ corresponding to the absorption of fluorenyl arms, the $\pi-\pi^{*}$ 
absorption in the UV range is clearly apparent but absent for TPP (1), see Fig. 5a. For compound 2, the four fluorenyl arms absorb in the UV range with a maximum absorption peak at $272 \mathrm{~nm}$, while for free bases 10,11 and $\mathbf{1 3}$ possessing only three arms, the absorption is weaker with a maximum at $275 \mathrm{~nm}$. At $425 \mathrm{~nm}$ is the $\mathrm{B}(0,0)$ band (Soret band), slightly red shifted compared to $417 \mathrm{~nm}$ for TPP (1), approximately as much as for TFP (2) (426 nm). This tendency in red shifting is observed as well for the $4 \mathrm{Q}$ bands.

The $\mathrm{Zn}$ (II) porphyrin complexes exhibit characteristic change in the electronic spectra compared to the free-base porphyrins. The absorption spectra of $\mathrm{Zn}$ (II) porphyrins display a single $\mathrm{Q}$ band absorption which is a combination of the $\mathrm{Q}_{\mathrm{X}}$ and $\mathrm{Q}_{\mathrm{Y}}$ bands due to the $D_{4 h}$ symmetry of metal porphyrins, instead of the $D_{2 h}$ symmetry of free base porphyrins, with two discernible sub-bands $(\mathrm{Q}(0,1)$ and $\mathrm{Q}(0,0)) .{ }^{24-26}$ Thus, the zinc complex 12 exhibit an intense Soret band at $426 \mathrm{~nm}$, together with two weak Q-bands in the visible range: located at $554 \mathrm{~nm}$ and $595 \mathrm{~nm}$ (Figure 5c and Table 1). An additional broad band is also observed in UV range which corresponds to $\pi-\pi^{*}$ absorption of the fluorenyl chromophores. This UV absorption, at $273 \mathrm{~nm}$, is weaker for the zinc complex 12 then reference TFP (2), due to the smaller number (three $v s$. four) of fluorenyl groups.

For porphyrin dimer, compound 7 - It shows the presence of a Soret band at $428 \mathrm{~nm}$ and four bands which are located at $513 \mathrm{~nm}(\mathrm{Qy}(0,1)$, very weak), $555 \mathrm{~nm}(\mathrm{Qy}(0,0)$, strong), $597 \mathrm{~nm}(\mathrm{Qx}(0,1)$, strong) and $643 \mathrm{~nm}(\mathrm{Qx}(0,0)$, weak), corresponding to the superposition of visible absorption of free base porphyrin $\left(\mathbf{H}_{2}\right.$ Por) and zinc complex (ZnPor). In addition, there is a wide band at $281 \mathrm{~nm}$ corresponding to the absorption of the six fluorenyls arms (Table 1).

2.3.2. Electronic spectra of titration - The formation of free dimer $\mathbf{8}$ by adding TFA to zinc complex 7 was followed by UV-Visible spectrophotometry (Figure 5b). During this titration, the Soret band, initially at $428 \mathrm{~nm}$, for dimer 7, is red shifted to $461 \mathrm{~nm}$, because protonation and consequently loss of encapsulated zinc.

In most cases, concerning protonation of a porphyrin monomer, because of small difference between stability constant $\left(\mathrm{K}_{3}\right.$ and $\left.\mathrm{K}_{4}\right)$ due to cooperative protonation, only two forms are observed by spectral methods: $:^{27}$ the neutral free base $\mathbf{H}_{2} \mathbf{P o r}$ and the dication H$_{4}$ Por $^{2+}$ :

\begin{tabular}{|c|c|c|c|c|}
\hline & $\mathrm{K}_{3}$ & & $\mathrm{~K}_{4}$ & \\
\hline $\mathbf{H}_{2} \mathbf{P c}$ & $\rightarrow$ & $\mathrm{H}_{3}$ Por $^{+}$ & $\rightarrow$ & $\mathbf{H}_{4}$ Por $^{2+}$ \\
\hline ase & & Monocation & & Dication \\
\hline
\end{tabular}


In our work, dissolution of dimer $\mathbf{7}$ writed $\mathbf{Z n P o r}-\mathbf{H}_{2}$ Por because composed of a zinc complex (ZnPor) and a free base $\left(\mathbf{H}_{2}\right.$ Por) in neutral DCM solution results in a UV-Vis spectrum with a maximum absorbance at $428 \mathrm{~nm}$, the evolution of visible spectra by protonation (adding regular small quantities of TFA) of starting $\mathbf{Z n P o r}-\mathbf{H}_{2}$ Por is shown in Fig. 5b. By adding TFA we have:

$$
\left[\mathrm{ZnPor}-\mathrm{H}_{2} \text { Por }\right] \rightarrow\left[\mathrm{ZnPor}-\mathrm{H}_{4} \text { Por }\right]^{2+} \rightarrow\left[\mathrm{H}_{4} \text { Por-H} \mathrm{H}_{4} \text { Por }\right]^{4+}
$$

In our case, the dication form $\left[\mathbf{Z n P o r}-\mathbf{H}_{4} \text { Por }\right]^{2+}$ is not observed, probably due to the small difference between stability constant, only the neutral form [ $\mathbf{Z n P o r}-\mathbf{H}_{2}$ Por] and the tetraprotonated form $\left[\mathbf{H}_{4} \text { Por- } \mathbf{H}_{4} \text { Por }\right]^{4+}$ are observed by UV-Visible.

The evolution of these spectra for both protonation steps has been followed by UV-Vis to understand the process, so we observe an isobestic point at $432 \mathrm{~nm}$; illustrating the formation of a distinct species: $\left[\mathbf{H}_{4} \text { Por- } \mathbf{H}_{4} \text { Por }\right]^{4+}$. For this tetracation porphyrin dimer, we observe the presence of a band at $461 \mathrm{~nm}$ and large band which is located at $684 \mathrm{~nm}$ corresponding to the superposition of Vis absorption of two similar protonated porphyrins. ${ }^{27}$ No evolution of the spectrum is observed if more acid is added. Then, we neutralize this tetracation $\left[\mathbf{H}_{4} \text { Por- }-\mathbf{H}_{4} \text { Por }\right]^{4+}$, by adding $\mathrm{NEt}_{3}$ :

\section{$\left[\mathrm{H}_{4} \text { Por }-\mathrm{H}_{4} \text { Por }\right]^{4+} \rightarrow\left[\mathrm{H}_{2}\right.$ Por- $-\mathrm{H}_{2}$ Por $]$}

The evolution of visible spectra by basifying is shown in Fig. 5b. Deprotonation occurred on titration with $\mathrm{NEt}_{3}$, transforming the $\left[\mathbf{H}_{4} \text { Por- } \mathbf{H}_{4} \mathbf{P o r}\right]^{4+}$ into the free base, so absorbance at $462 \mathrm{~nm}$ disappeared and an isobestic point at $432 \mathrm{~nm}$, is again observed. We can notice that the original spectrum of dimer $\mathbf{7}$, is not restored because of the irreversible loss of encapsulated zinc but no partial degradation is observed. A new form is obtained corresponding to the neutral species $\left[\mathbf{H}_{2}\right.$ Por- $\mathbf{H}_{2}$ Por $]$ named free dimer $\mathbf{8}$.

For free base porphyrin dimer 8 - It shows the presence of a Soret band at $426 \mathrm{~nm}$ : this band is slightly blue shifted compared to $428 \mathrm{~nm}$ for dimer $\mathbf{7}$, due to the loss of zinc. This tendency in blue shifting is not observed for the Q bands; they are slightly red shifted compared to dimer 7, and the relative intensities are different. They are located at $521 \mathrm{~nm}$ $(\mathrm{Qy}(0,1)$; strong), $557 \mathrm{~nm}(\mathrm{Qy}(0,0)$; strong), $595 \mathrm{~nm}(\mathrm{Qx}(0,1)$; strong) and $650 \mathrm{~nm}(\mathrm{Qx}(0$, 0 ); weak), corresponding typically to Visible absorption of a free porphyrin.

In addition, there is exaltation in UV absorption: a wide band at $268 \mathrm{~nm}$ corresponding to the absorption of the six fluorenyls arms is observed. We can notice in Figure 5a, that in this conjugated system possessing 6 fluorenyl arms and two porphyrin macrocycles, the antenna absorption is stronger for dimer 8, then for TFP possessing 4 arms per porphyrin heart. In Figure 5c the UV-Vis absorption of monomers 11, 12 and $\mathbf{1 3}$ are compared to the 
absorption of free dimer $\mathbf{8}$. The profiles of parents monomers 11, 12 (except Q bands) and $\mathbf{1 3}$ are quiet similar.

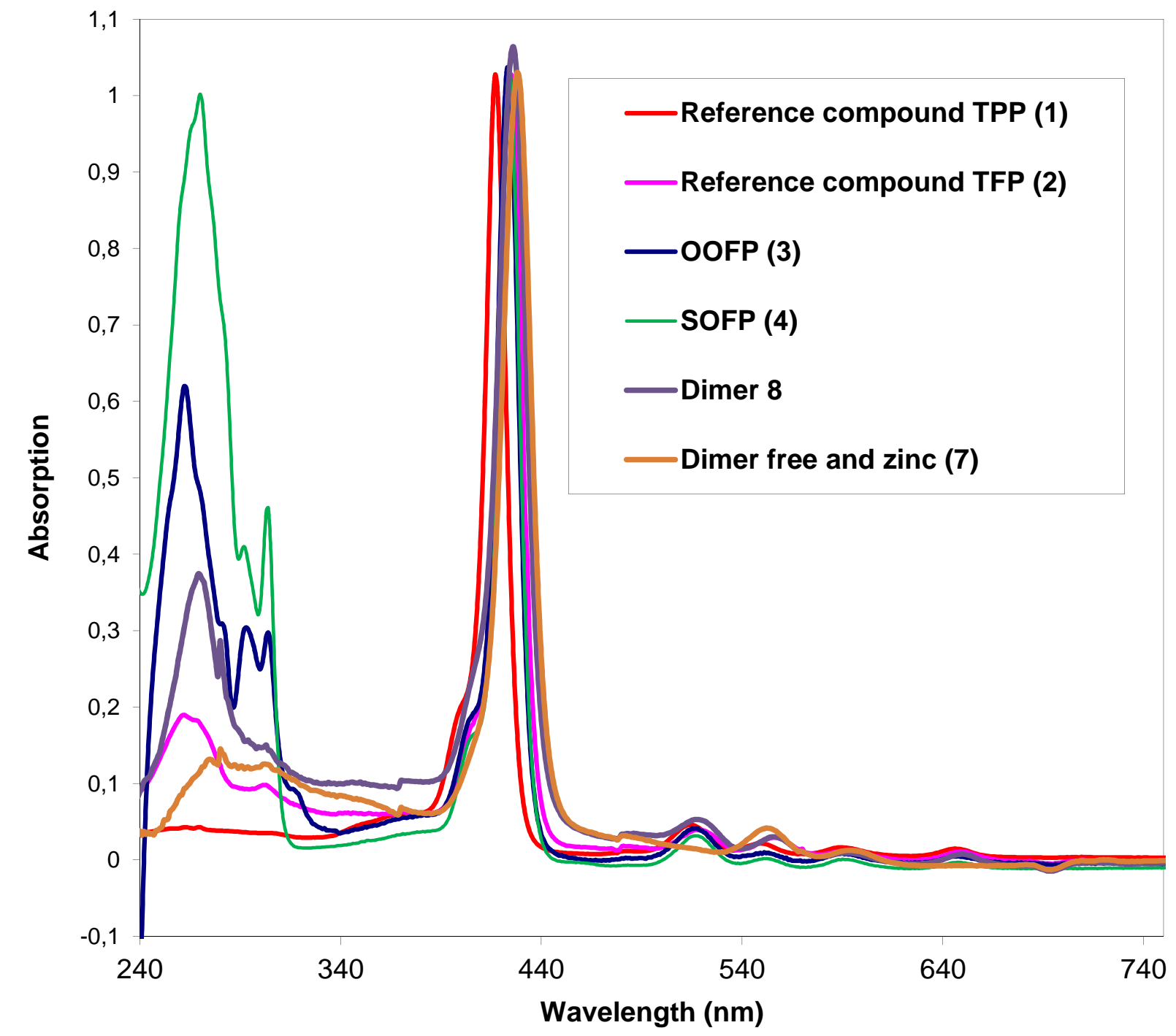

a/ 


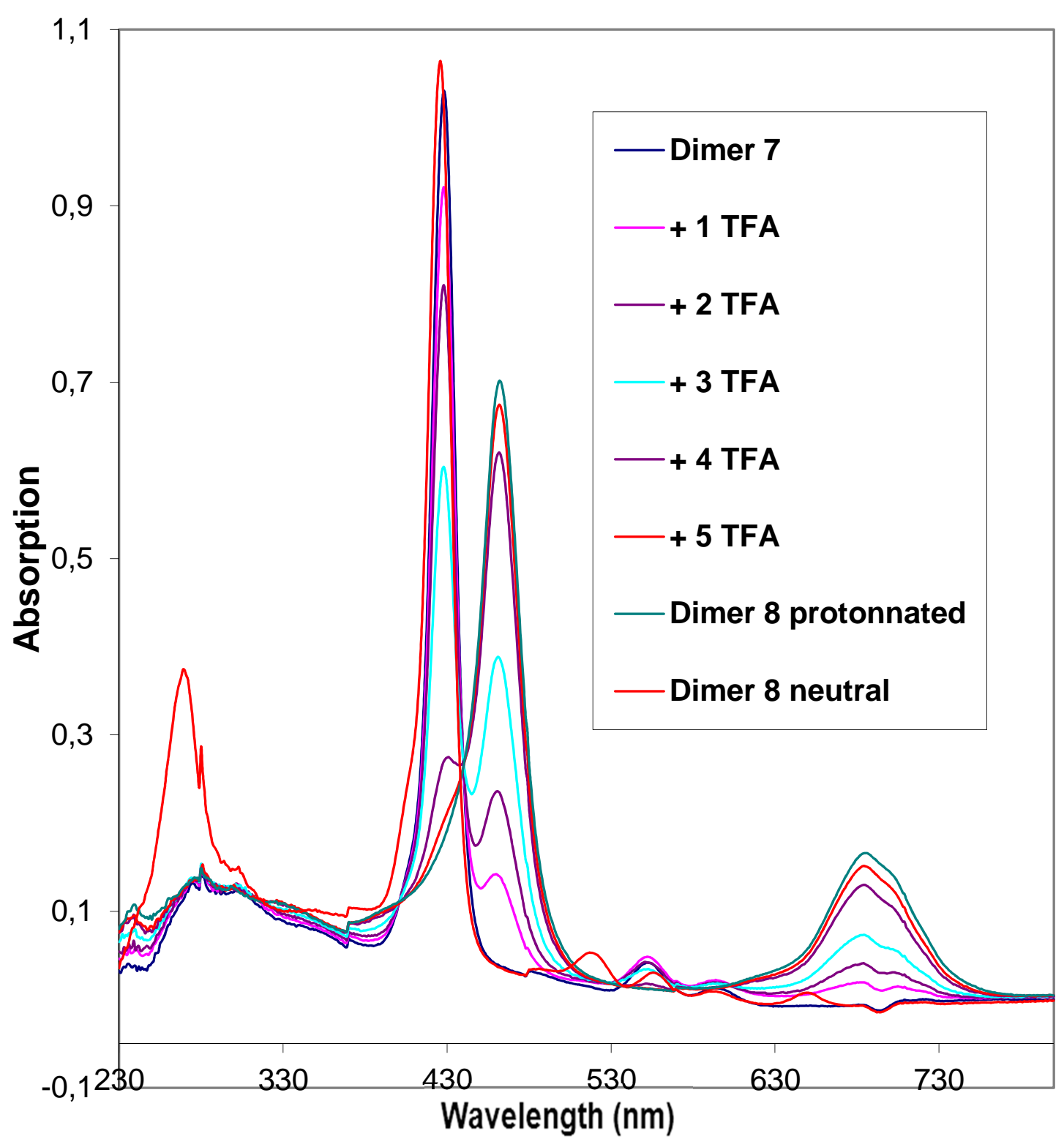

b/ 


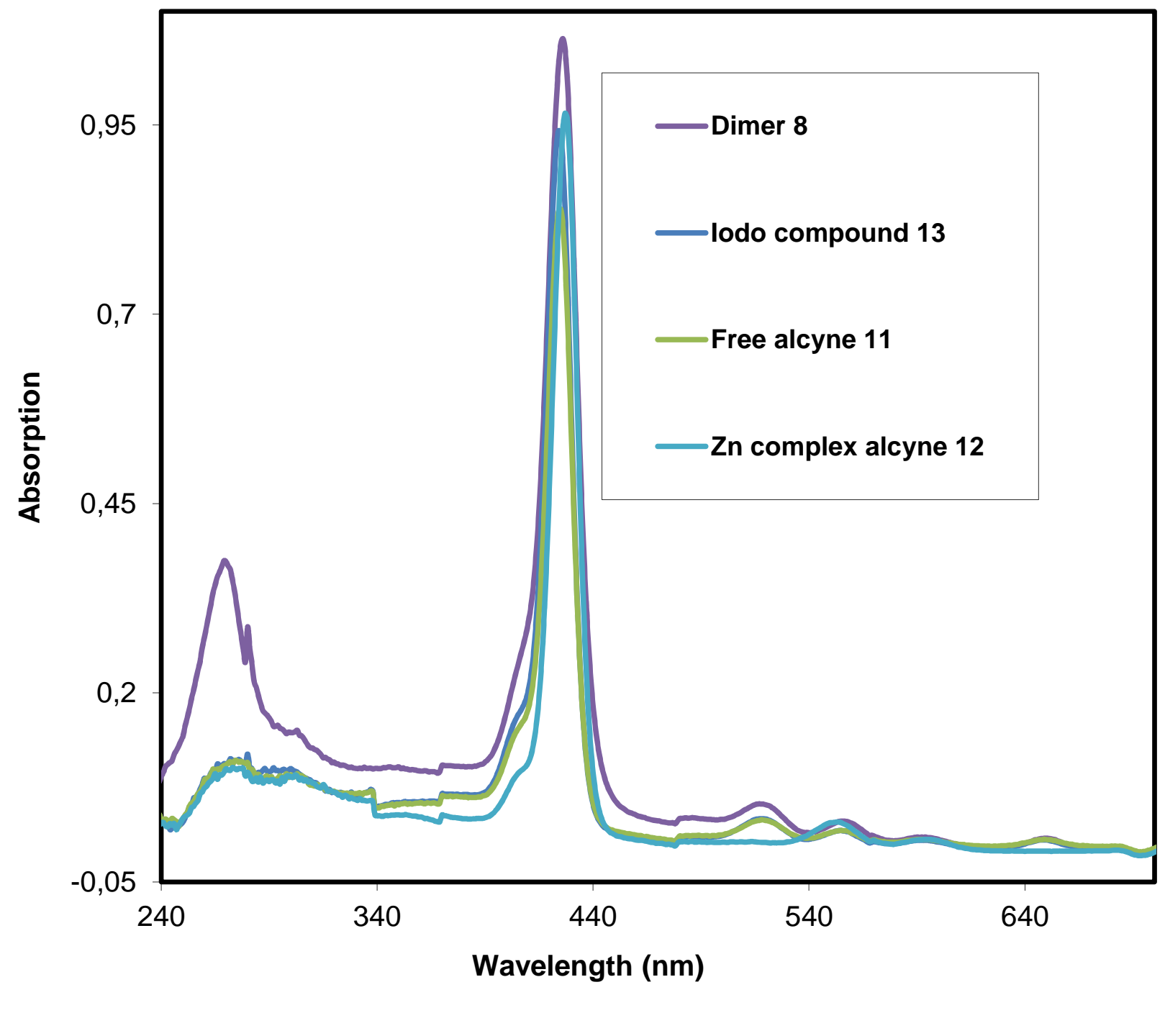

Figure 5: $\quad$ a/ Absorption spectra of TPP (red), TFP (pink), OOFP (dark blue), SOFP (green) and new dimers 7 (orange), $\mathbf{8}$ (violet) in DCM at room temperature. All the spectra are normalized to the spectrum of the reference TPP at $417 \mathrm{~nm}$ (concentration $\sim 2.010^{-6} \mathrm{M}$ ).

b/ Formation of free dimer $\mathbf{8}$ by protonation of zinc complex 7.

c/ Absorption spectra of precursors 11, 12, 13 and new dimer 8 in DCM at room temperature.

2.3.3. Emission spectroscopy - Generally, the emission spectra of porphyrin zinc complexes consist of three sub-bands assigned to a vibronic progression from a $\mathrm{Q}$ state: the band near $720 \mathrm{~nm}$ assigned as $\mathrm{Q}(2,0)$ is very weak and appears often as an extended tail on the $\mathrm{Q}(1,0)$ band. The strongest emission band $\mathrm{Q}(0,0)$ is typically around $600 \mathrm{~nm}$ and the second peak ; $\mathrm{Q}(1,0)$ at $\sim 650 \mathrm{~nm}$, due to the metal coordination. ${ }^{13}$

The fluorescence spectra at $25{ }^{\circ} \mathrm{C}$ of the zinc(II) complex 12, after excitation in the Soret band (or $\mathrm{B}(0,0)$ band) reveals a strong red fluorescence with a peak maximum $\mathrm{Q}(0,0)$ at 607 $\mathrm{nm}$ and a second peak, $\mathrm{Q}(1,0)$ at $655 \mathrm{~nm}$ (Fig. 6a). We can notice that the band near $720 \mathrm{~nm}$ assigned as $\mathrm{Q}(2,0)$, does not appear for this complex. 
For comparison, the emission spectrum of free iodo compound $\mathbf{1 3}$ is also reported. After excitation in the Soret band, a strong red emission at $663 \mathrm{~nm}$, assigned as $\mathrm{Q}(1,0)$, and a weaker shoulder at $728 \mathrm{~nm}$, assigned as $\mathrm{Q}(2,0)$ are observed (Fig. 6a). That means that by emission spectroscopy, we should be able to clearly identify the free base moiety $\mathbf{H}_{2}$ Por and the zinc complex moiety ZnPor of the dimer molecule [ZnPor- $\mathbf{H}_{2} \mathbf{P}$ Por]. Concerning, dimer $\mathbf{7}$, effectively; after excitation in the Soret band, a weak emission at $600 \mathrm{~nm}$, a strong red emission at $657 \mathrm{~nm}$ and a weaker shoulder at $720 \mathrm{~nm}$ are observed.

In conclusion for this compound 7, we clearly identify the free base part and the zinc complex part of the non-symmetrical dimer molecule [ZnPor-H $\mathbf{H}_{2}$ Por]. In the opposite for demetallated dimer $\mathbf{8}$, of type $\left[\mathbf{H}_{2}\right.$ Por- $\mathbf{H}_{2}$ Por $]$, possessing two similar free base moieties $\mathbf{H}_{2}$ Por, we observe as expected, two peaks: at $657(\mathrm{Q}(1,0))$ and $720 \mathrm{~nm}(\mathrm{Q}(2,0))$.

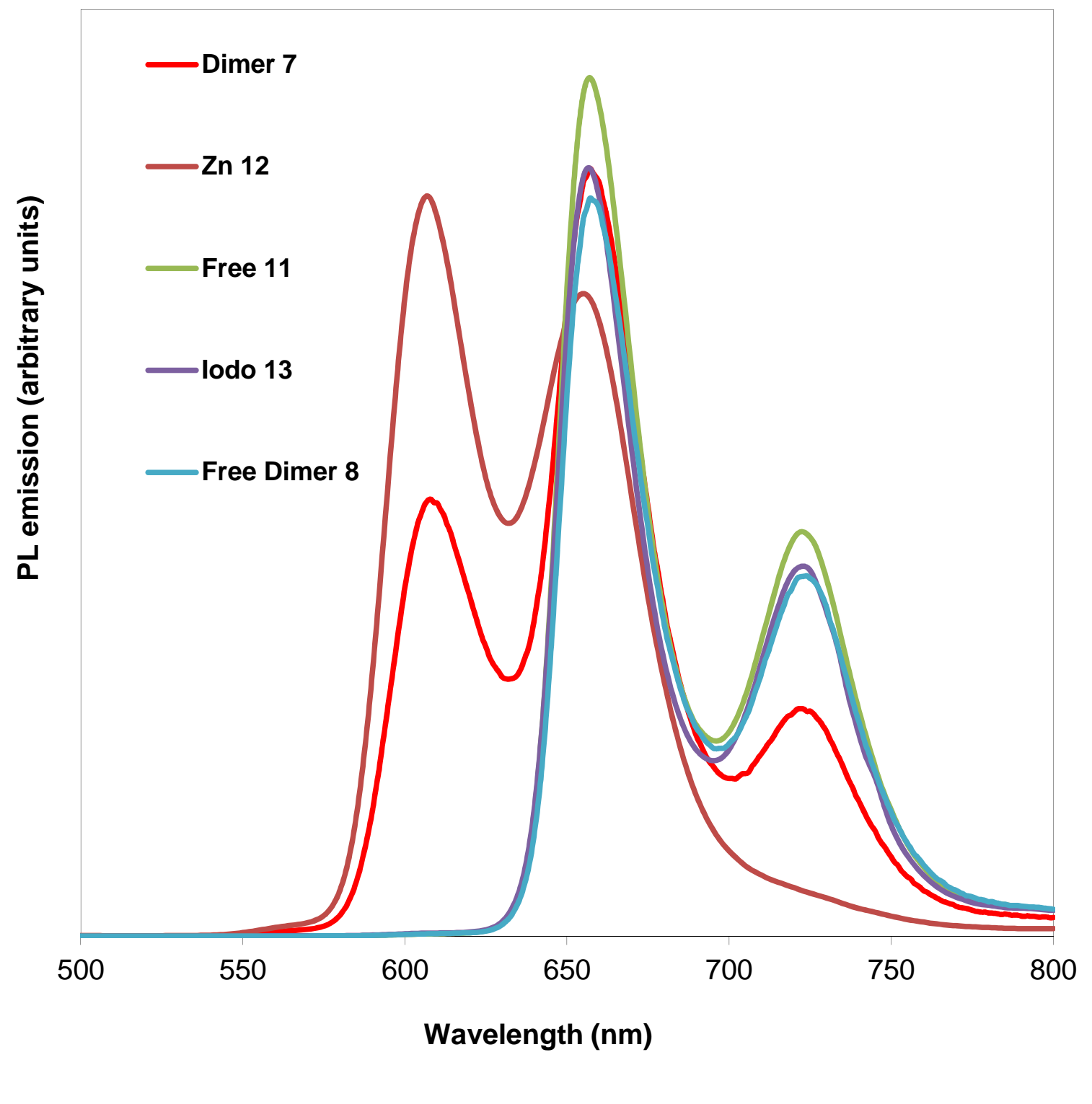




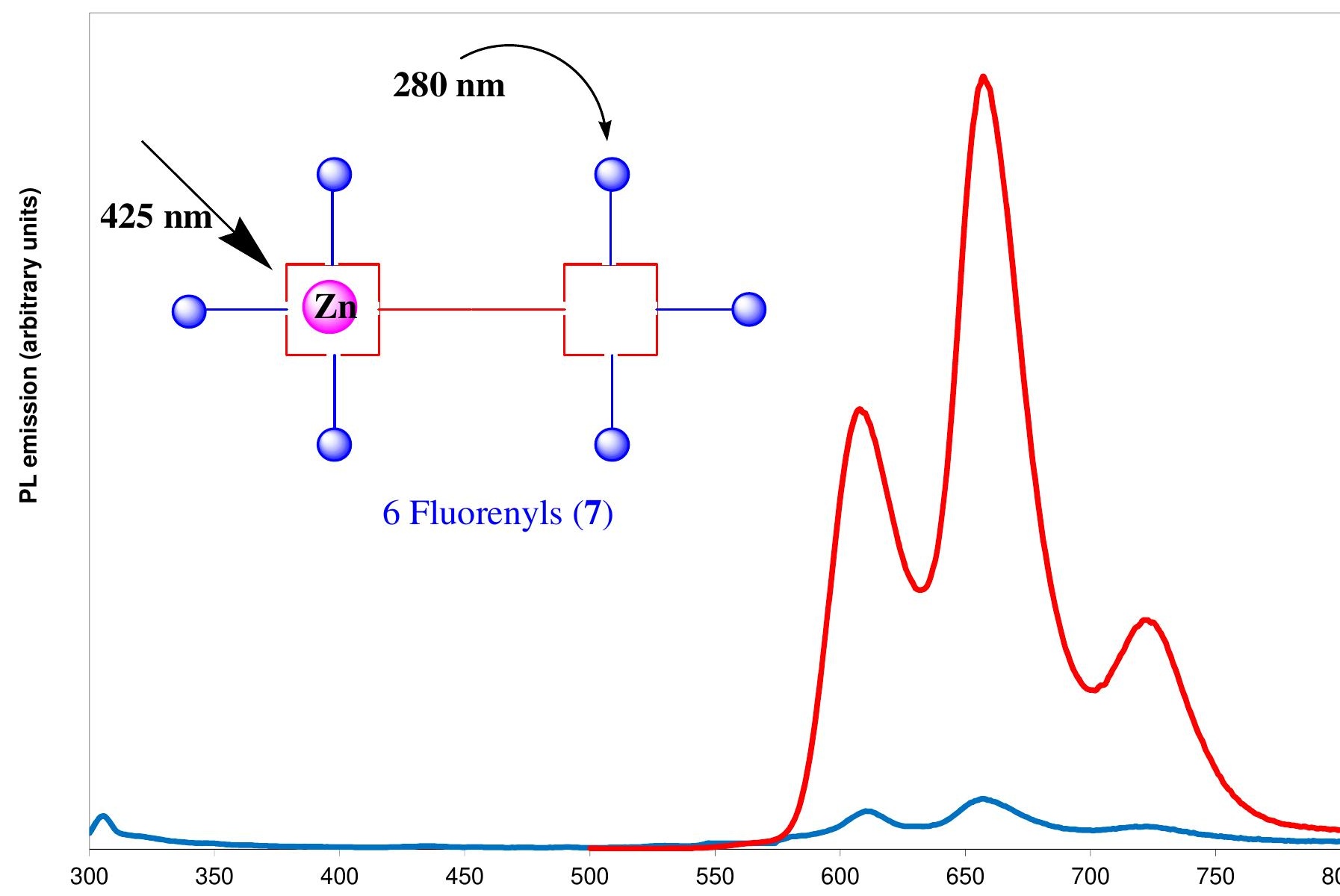

Wavelength (nm)

b/ 


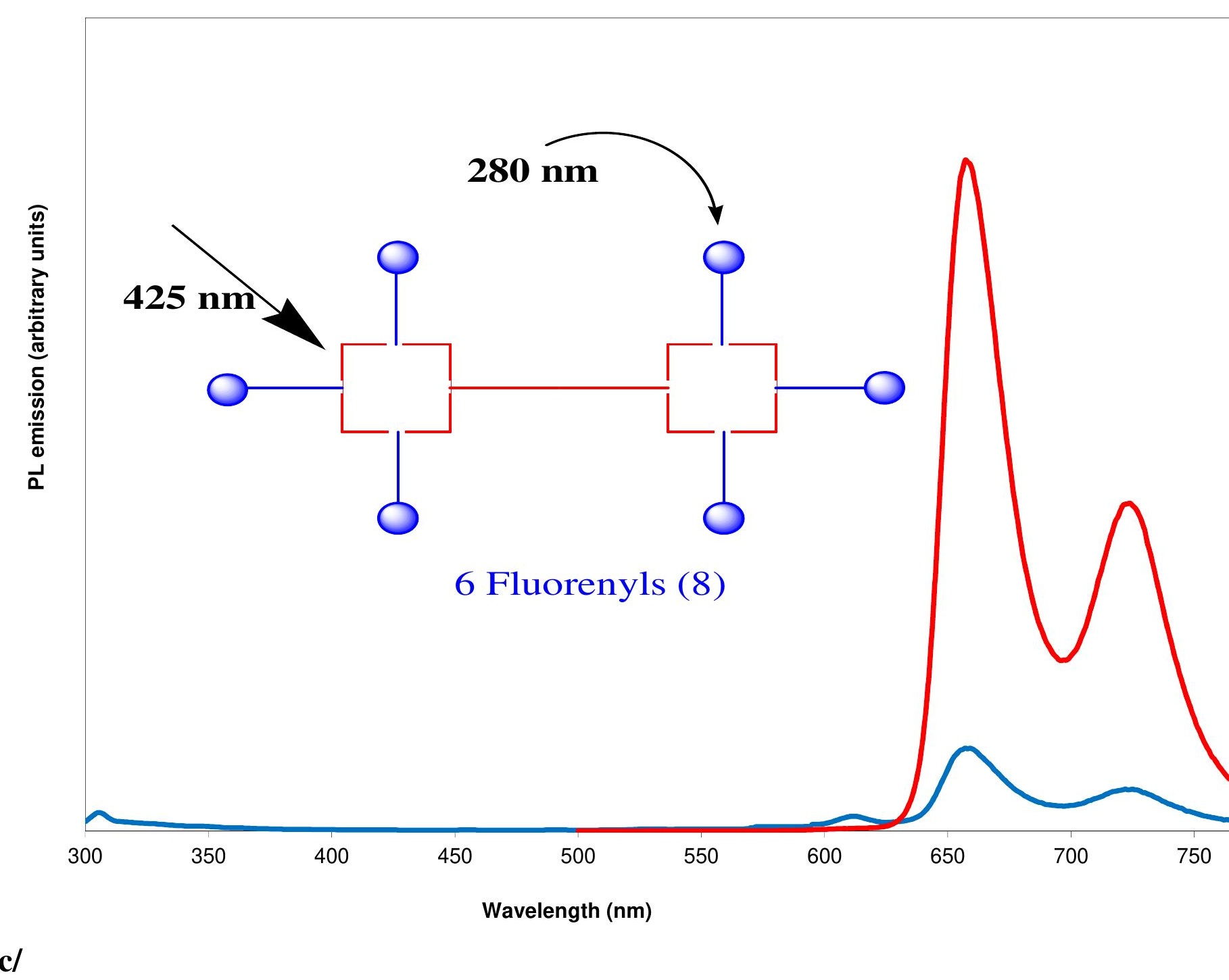




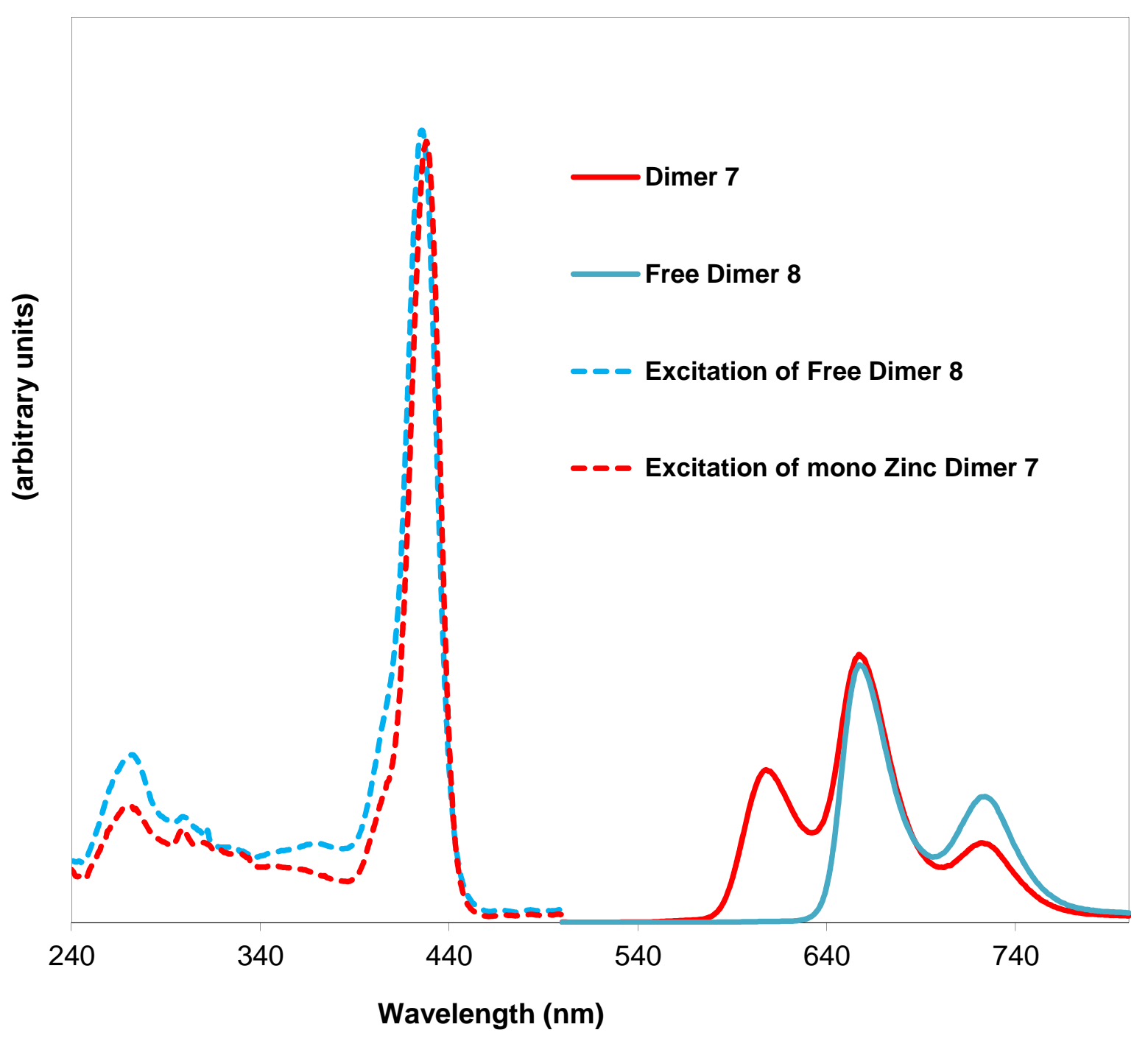

d/

Figure 6: $\quad$ a/ Emission spectra of monomers 11, 12 and 13 compared to dimers 7 and 8 in DCM at room temperature. All the spectra are normalized to the spectrum of dimer 7 at $657 \mathrm{~nm}$ (concentration $\sim 2.010^{-6} \mathrm{M}$ ).

b/ Fluorescence spectra of 7 in DCM at room temperature under single photon excitation conditions. A partial quenching of the donor emission is observed upon excitation of 7 at 280 $\mathrm{nm}$ (blue), resulting in a significant porphyrin emission from $\mathbf{7}$, compared to direct emission of 7 at $425 \mathrm{~nm}$ (red).

c/ Fluorescence spectra of $\mathbf{8}$ in DCM at room temperature under single photon excitation conditions. A partial quenching of the donor emission is observed upon excitation of $\mathbf{8}$ at 280 $\mathrm{nm}$ (blue), resulting in a significant porphyrin emission from $\mathbf{8}$, compared to direct emission of 7 at $425 \mathrm{~nm}$ (red).

d/ Photoluminescence spectra of dimer 7 (plain red) and $\mathbf{8}$ (plain blue) in $\mathrm{CH}_{2} \mathrm{Cl}_{2}$ solution $\left(\sim 1.010^{-6} \mathrm{M}\right)$, at $25^{\circ} \mathrm{C}$, the emission spectra were cut above $800 \mathrm{~nm}$. Excitation spectra of compounds 7 (dashed red) and 8 (dashed blue) at $650 \mathrm{~nm}$.

2.3.4. Energy transfer - The efficiently of energy transfer from fluorenyl donors toward porphyrin acceptor will be discussed. Excitation of dimers $\mathbf{7}$ and $\mathbf{8}$ in the fluorenyl antennae results in the red emission of porphyrins with a max at $657 \mathrm{~nm}$ in both cases. Effectively, the blue fluorenyl emission is partly quenched for dimer 7, almost completely 
quenched for free dimer $\mathbf{8}$, and red emission is seen predominantly from the porphyrin (Figure $6 \mathrm{~b}$ and c). We have to notice that, when excited directly at $425 \mathrm{~nm}$, dimers $\mathbf{7}$ and $\mathbf{8}$ show a strong red emission in comparison to the indirect excitation at $280 \mathrm{~nm}$. But this is not evidence of inefficient energy transfer but of a more complex process. ${ }^{28}$

The excitation spectrum of compound 7 around $657 \mathrm{~nm}$ (Fig. 6d) reveals that the strong emission from the Soret state is populated when the fluorenyl band is excited. This indicates that excitation over all the $200-650 \mathrm{~nm}$ region leads to the population of the fluorescent excited states of the porphyrin, as the fluorene absorption becomes apparent under such excitation conditions. For comparison, the corresponding excitation spectrum of free dimer $\mathbf{8}$ is also shown in Fig. 6d, and we can see an enhancement in the UV region due to the fluorenyl arms for the latter.

Thus for these compounds $\mathbf{7}$ and $\mathbf{8}$, the luminescence can be modulated in a large range of excitation wavelengths from UV to red, to finally obtain the desired red emission.

2.3.5. Fluorescence quantum yields - The fluorescence quantum yields of these compounds were next determined by comparing with a calibration standard of compound 1 (TPP) in degassed toluene solution presenting a fluorescence quantum yield of $0.12,{ }^{29}$ preferentially to a benzene solution with a fluorescence quantum yield of $0.13 .^{30}$ [In this latter case, different refractive indices of the solvents used in the standard and sample must be corrected. ${ }^{31}$ In consequence the correction made for the difference in refractive indices of solvents is in this case not necessary.] The quantum yield was calculated from the following equation:

$$
\Phi_{\mathrm{s}}=\Phi_{\mathrm{TPP}} \times\left(\mathrm{F}_{\mathrm{S}} / \mathrm{F}_{\mathrm{TPP}}\right) \times\left(\mathrm{A}_{\mathrm{TPP}} / \mathrm{A}_{\mathrm{s}}\right) \times\left(\mathrm{n}_{\mathrm{TPP}} / \mathrm{n}_{\mathrm{s}}\right)^{2}
$$

In the above expression, $\boldsymbol{\Phi}_{\mathbf{s}}$ is the fluorescent quantum yield of the new compound, $\mathbf{F}$ is the integration of the emission intensities, $\mathrm{n}$ is the index of refraction of the solution, and $\mathbf{A}$ is the absorbance of the solution at the exciting wavelength. The subscripts TPP and s denote the reference (TPP) and unknown samples, respectively. ${ }^{32}$

Values of quantum yield obtained in degassed toluene, of free ligands 1, 2, 3 and 4 are reported in Table 1. Compounds 3 and $\mathbf{4}$ present a luminescence quantum yield (13 and 14\% respectively), which is similar to that of the reference $\mathbf{1}(12 \%)$. We showed earlier that increasing the number of dendrons does have any significant influence on the quantum yield. As a result, a system in which a 5,10,15,20-tetraphenylporphyrin is linked, via ether bridges, 
to eight or sixteen fluorenyl donor moieties in position 3 and 5, presents the same luminescence efficiency as the parent TPP compound. ${ }^{20,28}$ For these reasons dimer with direct connection of fluorenyl on meso position was proposed.

For free dimer 8: a conjugated system possessing 6 fluorenyl arms and two free porphyrin macrocycles, a high luminescence quantum yield (17\%) is obtained in nondegassed DCM, higher than previous none conjugated dendrimers; with 8 or 16 fluorenyl arms (compounds 3 and $\mathbf{4}$ respectively) and as the reference TPP compound (1), but not as high as the parent compound TFP (2).

The corresponding zinc complexes, monomer 12 and dimer 7 have low luminescence quantum yield (around 5-7\%), which is relatively high for zinc complexes, higher than reference compound ZnTPP (3.3\%) and similar to the parent compound ZnTFP (5\%). ${ }^{13}$

\begin{tabular}{|c|c|c|c|c|c|}
\hline Porphyrin & $\lambda_{\max } / \mathrm{nm}^{(a)}$ & $\lambda_{\max } / \mathrm{nm}^{(b)}$ & $\begin{array}{c}\lambda_{\max } / \mathrm{nm} \\
\text { UV band }\end{array}$ & $\begin{array}{c}\lambda_{\mathrm{em}} / \mathrm{nm} \\
\text { Soret band }\end{array}$ & $\Phi_{\mathrm{f}}^{(c)}$ \\
\hline TPP (1) & - & 417 & $513,548,589,646$ & 650,714 & 0.12 \\
\hline TFP (2) & 272 & 426 & $519,557,593,649$ & 661,725 & 0.24 \\
\hline OOFP(3) & 263 & 423 & $516,551,592,653$ & 656,721 & 0.13 \\
\hline SOFP (4) & 270 & 423 & $517,552,590,647$ & 656,721 & 0.14 \\
\hline Free 11 & 275 & 425 & $518,555,594,649$ & 657,700 & 0.21 \\
\hline Zn (12) & 273 & 426 & 554,595 & 607,655 & 0.07 \\
\hline Iodo (13) & 275 & 424 & $519,555,593,649$ & 663,728 & 0.05 \\
\hline Dimer (7) & 281 & 428 & $513,555,597,643$ & $600,657,720$ & 0.05 \\
\hline Free Dimer (8) & 268 & 426 & $521,557,595,650$ & 657,720 & 0.17 \\
\hline
\end{tabular}

(a) Wavelengths of the absorption maxima in the UV region (200-400 $\mathrm{nm}$ range)

(b) Wavelengths of the absorption maxima in the Soret or B band region (400-450 $\mathrm{nm}$ range)

(c) Fluorescence quantum yields using TPP in DCM as standard, following excitation into the Soret bands

Table 1: $\quad$ Photophysical properties of the fluorenyl porphyrins 1, 2, 3 and 4 in dilute $\mathrm{CH}_{2} \mathrm{Cl}_{2}$ solution at 298K, and of dimers 7 and 8, zinc complex 12 and free base 11, 13, under the same conditions for comparison.

\section{Conclusions and outlook}

In summary, a series of highly luminescent intermediate porphyrins bearing three fluorenyl groups was presented, successively, compounds 10, 11, 12 and 13. Starting from these building blocks, new linear dimers $\mathbf{7}$ and $\mathbf{8}$, bearing in totally six peripheral fluorenyl arms were synthesised and fully characterized. We compared the luminescence properties of 
these new dimers with the reference TPP (1), porphyrin dendrimers (3 and 4), but also with TFP (2), which was the promising precursor model of this work.

Perspectives may be changing the bridge connecting the two porphyrins of the assembly to optimize the luminescence, and eventually extend this work to corresponding trimers synthesis. We can also consider grafting dendrons at the periphery of these new dimers, still in the idea of increasing the number of antennae around the heart porphyrin for light collection.

\section{Experimental section}

\subsection{General procedures}

All reactions were performed under argon and were magnetically stirred. Solvents were distilled from appropriate drying agent prior to use, DCM and $\mathrm{CHCl}_{3}$ from $\mathrm{CaH}_{2}$ and THF was distilled using sodium/benzophenone system. The rest of the solvents used were of HPLC grade. Commercially available reagents were used without further purification unless otherwise stated. Pyrrole and 2-fluorenecarboxaldehyde were purchased from Aldrich and were used as received. References TFP $=$ tetrafluorenylporphyrin, $\mathbf{T P P}=$ tetraphenylporphyrin.

${ }^{1} \mathrm{H}$ NMR and ${ }^{13} \mathrm{C}$ NMR in $\mathrm{CDCl}_{3}$ were recorded using Bruker $200 \mathrm{DPX}, 300 \mathrm{DPX}$ and 500 DPX spectrometers. The chemical shifts are referenced to internal TMS. The assignments were performed by 2D NMR experiments: COSY (Correlation Spectroscopy), HMBC (Heteronuclear Multiple Bond Correlation) and HMQC (Heteronuclear Multiple Quantum Coherence). UV spectra were recorded on UVIKON XL from Biotek instruments. PL emission was recorded on a Photon Technology International (PTI) apparatus coupled on an 814 Photomultiplier Detection System, Lamp Power Supply 220B and MD-5020. Steady-state fluorescence measurements were performed at R.T. on dilute solutions (ca. $10^{-6} \mathrm{M}$ ) using an Edinburgh Instruments (FLS 920) spectrometer working in photon-counting mode, equipped with a calibrated quantum counter for excitation correction. Fluorescence quantum yields were measured using standard methods; TPP in DCM $\left(\Phi=0.12\right.$ at $\left.\lambda_{\mathrm{ex}}=417 \mathrm{~nm}\right)$ was used as a reference. The reported fluorescence quantum yields are within $\pm 10 \%$.

\subsection{Synthesis of Monomers}


4.2.1. Synthesis of 4-((trimethylsilyl)ethynyl)benzaldehyde 9 was described earlier ${ }^{23}$ Trimethylsilylacetylene $(5 \mathrm{~mL}, 4.03 \mathrm{~g}, 41.0 \mathrm{mmol})$ was added to a solution of 4bromobenzaldehyde (5.00 g, $27.0 \mathrm{mmol}), \mathrm{Pd}\left(\mathrm{PPh}_{3}\right)_{2} \mathrm{Cl}_{2}(50 \mathrm{mg}, 0.07 \mathrm{mmol})$ and $\mathrm{CuI}(25 \mathrm{mg}$, $0.13 \mathrm{mmol})$ in distilled THF $(40 \mathrm{~mL})$ under argon. Then, triethylamine $(6.5 \mathrm{~mL})$ was added and the reaction mixture was heated at $40 \mathrm{C}$ overnight. The solvent was evaporated under reduced pressure. The obtained residue was extracted in DCM, washed in water, dried with $\mathrm{MgSO}_{4}$, and then taken into dryness. The solid was then purified by column chromatography on silica gel using a mixture of heptane/DCM $(1: 1)$ as eluent. The compound 9 was obtained as a pale yellow solid to yield $5.04 \mathrm{~g}(92 \%) .{ }^{1} \mathbf{H}$ NMR $\left(400 \mathrm{MHz}, \mathrm{CDCl}_{3}, \delta\right.$ in ppm) : 10.01 (s, $1 \mathrm{H}, \mathrm{CHO}), 7.83\left(\mathrm{~d}, 2 \mathrm{H}, \mathrm{H}_{\text {phenyl }},{ }^{3} \mathrm{~J}_{\mathrm{HH}}=7.6 \mathrm{~Hz}\right), 7.62\left(\mathrm{~d}, 2 \mathrm{H}, \mathrm{H}_{\text {phenyl }},{ }^{3} \mathrm{~J}_{\mathrm{HH}}=7.2 \mathrm{~Hz}\right), 0.29(\mathrm{~s}$, $\left.9 \mathrm{H},\left(\underline{\mathrm{C}}_{3}\right)_{3} \mathrm{Si}\right)$.

\subsubsection{Synthesis of 5,10,15-(trifluorenyl)-20-(4-((trimethylsilyl)ethynyl)phenyl)}

porphyrin 10 - 2-Fluorenylcarboxylaldehyde (3.00 g, $15.4 \mathrm{mmol})$, 4-(trimethylsilyl)ethynyl benzaldehyde $(1.00 \mathrm{~g}, 5.0 \mathrm{mmol})$ and pyrrole $(1.4 \mathrm{~mL}, 20.0 \mathrm{mmol})$ were added to distilled chloroform $(1.5 \mathrm{~L})$ in a double necked round bottom flask under argon. The flask was covered with aluminium foil since the reaction is light sensitive at this stage. Boron trifluoride diethyl etherate, $\mathrm{BF}_{3} . \mathrm{OEt}_{2}(560 \mu \mathrm{L})$ was added, and the reaction was kept at room temperature for three hours. Then, three equivalents of $p$-chloranil $(3.78 \mathrm{~g}, 15.4 \mathrm{mmol})$ were added and the solution was heated to reflux (light protection was removed). After $1 \mathrm{~h}$, the solution was cooled to room temperature. Two pipettes of triethylamine were added to neutralize the reaction mixture. Solvent was evaporated and the residue was filtered over silica with heptane/DCM (65:35) and then (45:55). The solid obtained was subjected to a second column chromatography of silica using the eluent heptane/DCM (70:30). The expected compound 10 was obtained as a purple solid to yield $756 \mathrm{mg}$ (15\%). New intermediate porphyrin 10 was fully characterized. ${ }^{1} \mathbf{H}$ NMR $\left(400 \mathrm{MHz}, \mathrm{CDCl}_{3}, \delta\right.$ in ppm) : $8.92(\mathrm{~d}, 2 \mathrm{H}$, ${ }^{3} \mathrm{~J}_{\mathrm{HH}}=5.0 \mathrm{~Hz}, \mathrm{H}_{\beta \text {-pyrrolic }}$ ), 8.91 (s, 4H, $\left.\mathrm{H}_{\beta \text {-pyrrolic }}\right), 8.82\left(\mathrm{~d}, 2 \mathrm{H},{ }^{3} \mathrm{~J}_{\mathrm{HH}}=4.4 \mathrm{~Hz}, \mathrm{H}_{\beta \text {-pyrrolic }}\right.$ ), 8.38 ( $\mathrm{s}$, $\left.3 \mathrm{H}, \mathrm{H}_{\text {fluorenyl }}, \mathrm{H}_{1}\right), 8.25\left(\mathrm{~d}, 3 \mathrm{H},{ }^{3} \mathrm{~J}_{\mathrm{HH}}=7.6 \mathrm{~Hz}, \mathrm{H}_{\text {fluorenyl }}, \mathrm{H}_{4}\right), 8.17\left(\mathrm{~m}, 5 \mathrm{H}, 2 \mathrm{H}_{\text {phenyl }}\right.$ and $\left.3 \mathrm{H}_{\text {fluorenyl: }} \mathrm{H}_{3}\right), 8.06\left(\mathrm{~d}, 3 \mathrm{H},{ }^{3} \mathrm{~J}_{\mathrm{HH}}=8.0 \mathrm{~Hz}, \mathrm{H}_{\text {fluorenyl }}, \mathrm{H}_{5}\right), 7.87\left(\mathrm{~d}, 2 \mathrm{H},{ }^{3} \mathrm{~J}_{\mathrm{HH}}=8.4 \mathrm{~Hz}, \mathrm{H}_{\text {phenyl }}\right)$, $7.70\left(\mathrm{~d}, 3 \mathrm{H},{ }^{3} \mathrm{~J}_{\mathrm{HH}}=7.2 \mathrm{~Hz}, \mathrm{H}_{\text {fluorenyl }}, \mathrm{H}_{8}\right), 7.52\left(\mathrm{~m}, 3 \mathrm{H}, \mathrm{H}_{\text {fluorenyl }}, \mathrm{H}_{6}\right), 7.44\left(\mathrm{~m}, 3 \mathrm{H}, \mathrm{H}_{\text {fluorenyl }}\right.$,

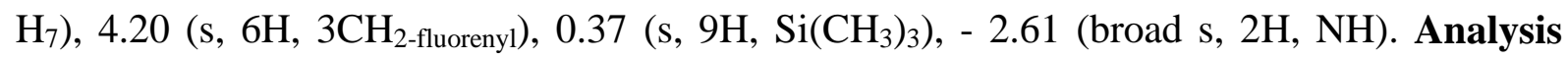
calcd for $\mathrm{C}_{70} \mathrm{H}_{50} \mathrm{~N}_{4} \mathrm{Si}^{\cdot 0.5 \mathrm{CHCl}_{3}}: \mathrm{C}, 81.82, \mathrm{H}, 4.92, \mathrm{~N}, 5.14$, found : C, 81.88, H, 6.06; N, 4.71. MALDI-TOF MS calcd for $\mathrm{C}_{70} \mathrm{H}_{50} \mathrm{~N}_{4} \mathrm{Si}: 975.38047[\mathrm{MH}]^{+}$, found : $975.43900[\mathrm{MH}]^{+}$. 
4.2.3. Synthesis of 5,10,15-(trifluorenyl)-20-(4-ethynylphenyl)porphyrin 11 Potassium carbonate $(145 \mathrm{mg}, 1.05 \mathrm{mmol})$ was added to a solution of porphyrin $\mathbf{1 0}(200 \mathrm{mg}$, $0.21 \mathrm{mmol})$ in distilled DCM $(36 \mathrm{~mL})$ and methanol $(12 \mathrm{~mL})$ under argon. The reaction mixture was stirred at room temperature for 47 hours. Then solvent was evaporated under reduced pressure. The obtained residue was extracted in dichloromethane, washed with $10 \%$ (v/v) aqueous solution of sodium hydrogen carbonate, dried with $\mathrm{MgSO}_{4}$, and then taken into dryness. The solid obtained was filtered over silica with DCM as an eluent. The deprotected porphyrin 11 was obtained as a purple powder to yield $187 \mathrm{mg}(98 \%)$. This new intermediate porphyrin 11 was fully characterized. ${ }^{1} \mathbf{H}$ NMR $\left(400 \mathrm{MHz}, \mathrm{CDCl}_{3}, \delta\right.$ in ppm) : $8.94(\mathrm{~d}, 2 \mathrm{H}$, $\left.{ }^{3} \mathrm{~J}_{\mathrm{HH}}=5.0 \mathrm{~Hz}, \mathrm{H}_{\beta \text {-pyrrolic }}\right), 8.92\left(\mathrm{~s}, 4 \mathrm{H}, \mathrm{H}_{\beta \text {-pyrrolic }}\right), 8.84\left(\mathrm{~d}, 2 \mathrm{H},{ }^{3} \mathrm{~J}_{\mathrm{HH}}=4.4 \mathrm{~Hz}, \mathrm{H}_{\beta \text {-pyrrolic }}\right), 8.39$ (s, $\left.3 \mathrm{H}, \mathrm{H}_{\text {fluorenyl, }} \mathrm{H}_{1}\right), 8.25\left(\mathrm{~d}, 3 \mathrm{H},{ }^{3} \mathrm{~J}_{\mathrm{HH}}=7.6 \mathrm{~Hz}, \mathrm{H}_{\text {fluorenyl, }} \mathrm{H}_{4}\right), 8.17\left(\mathrm{~m}, 5 \mathrm{H}, 2 \mathrm{H}_{\text {phenyl }}\right.$ and $3 \mathrm{H}_{\text {fluorenyl, }}$ $\left.\mathrm{H}_{3}\right), 8.06\left(\mathrm{~d}, 3 \mathrm{H},{ }^{3} \mathrm{~J}_{\mathrm{HH}}=7.6 \mathrm{~Hz}, \mathrm{H}_{\text {fluorenyl, }} \mathrm{H}_{5}\right), 7.89\left(\mathrm{~d}, 2 \mathrm{H},{ }^{3} \mathrm{~J}_{\mathrm{HH}}=8.0 \mathrm{~Hz}, \mathrm{H}_{\text {phenyl }}\right), 7.70(\mathrm{~d}, 3 \mathrm{H}$, $\left.{ }^{3} \mathrm{~J}_{\mathrm{HH}}=7.2 \mathrm{~Hz}, \mathrm{H}_{\text {fluorenyl }}, \mathrm{H}_{8}\right), 7.53\left(\mathrm{~m}, 3 \mathrm{H}, \mathrm{H}_{\text {fluorenyl }}, \mathrm{H}_{6}\right), 7.44\left(\mathrm{~m}, 3 \mathrm{H}, \mathrm{H}_{\text {fluorenyl }}, \mathrm{H}_{7}\right), 4.21(\mathrm{~s}, 6 \mathrm{H}$, $3 \mathrm{CH}_{2 \text {-fluorenyl }}$ ), 3.31 (s, 1H, $\mathrm{C}_{\text {alkyne- }} \mathrm{H}$ ), - 2.65 (broad s, 2H, NH). Rf on silica plate using DCM / heptane (60 : 40): 0.46. FT-IR $\left(\mathrm{n}, \mathrm{KBr}, \mathrm{cm}^{-1}\right): 2106(\mathrm{C} \equiv \mathrm{C})$. UV-vis $\left(\lambda \max ,\left(\varepsilon, 10^{-3} \mathrm{M}^{-1} . \mathrm{cm}^{-}\right.\right.$ $\left.\left.{ }^{1}\right), \mathrm{CH}_{2} \mathrm{Cl}_{2}, \mathrm{~nm}\right): 275$ (83), 425 (624), 519 (24), 556 (14), 593 (4.7), 649 (4.9). Analysis calcd for $\mathrm{C}_{67} \mathrm{H}_{42} \mathrm{~N}_{4} \mathrm{CH}_{3} \mathrm{OH}: \mathrm{C}, 87.34, \mathrm{H}, 4.96, \mathrm{~N}, 5.99$, found : C, 87.51, $\mathrm{H}, 5.08, \mathrm{~N}, 5.70$. MALDI-TOF MS : calcd for $\mathrm{C}_{67} \mathrm{H}_{42} \mathrm{~N}_{4}: 903.34877[\mathrm{MH}]^{+}$, found : $903.3400[\mathrm{MH}]^{+}$. MS (ESI) : calcd for $\mathrm{C}_{67} \mathrm{H}_{42} \mathrm{~N}_{4}$ : $925.33072[\mathrm{MNa}]^{+}$, $903.34877[\mathrm{MH}]^{+}$, found : $925.3305[\mathrm{MNa}]^{+}$, $903.3471[\mathrm{MH}]^{+}$.

4.2.4. Synthesis of Zn(II)-5,10,15-(trifluorenyl)-20-(4-ethynylphenyl)porphyrinato 12 $\mathrm{Zn}\left(\mathrm{CH}_{3} \mathrm{CO}_{2}\right)_{2} .2 \mathrm{H}_{2} \mathrm{O}(220 \mathrm{mg}, 1.0 \mathrm{mmol})$ was added to a solution of porphyrin $11(185 \mathrm{mg}$, $0.2 \mathrm{mmol})$ in distilled DCM $(127 \mathrm{~mL})$ and methanol $(63 \mathrm{~mL})$ under argon. The reaction mixture was stirred during $24 \mathrm{~h}$ at room temperature. The reaction progress was monitored by UV-visible spectroscopy and by TLC, spotting directly from the organic layer. Solvent was evaporated under reduced pressure. The obtained residue was extracted in dichloromethane, washed with $10 \%(\mathrm{v} / \mathrm{v})$ aqueous solution of sodium hydrogen carbonate, dried with $\mathrm{MgSO}_{4}$, and then taken into dryness. The solid obtained was filtered over silica with DCM as an eluent. The metallated porphyrin 12 was obtained as a purple solid to yield $188 \mathrm{mg}$ (97\%). The new zinc porphyrin complex, 12 was fully characterized; the hydrogen and carbon atomlabeling scheme for this monomer is shown in Figure 2. ${ }^{\mathbf{1}} \mathbf{H} \mathbf{~ N M R}\left(400 \mathrm{MHz}, \mathrm{CDCl}_{3}, \delta\right.$ in 
ppm) : $9.04\left(\mathrm{~d}, 2 \mathrm{H},{ }^{3} \mathrm{~J}_{\mathrm{HH}}=5.0 \mathrm{~Hz}, \mathrm{H}_{\beta \text {-pyrrolic }}\right), 9.02\left(\mathrm{~s}, 4 \mathrm{H}, \mathrm{H}_{\beta \text {-pyrrolic }}\right), 8.93\left(\mathrm{~d}, 2 \mathrm{H},{ }^{3} \mathrm{~J}_{\mathrm{HH}}=4.4\right.$ $\mathrm{Hz}, \mathrm{H}_{\beta \text {-pyrrolic }}$ ), 8.39 (s, 3H, $\left.\mathrm{H}_{\text {fluorenyl }}, \mathrm{H}_{1}\right), 8.25$ (d, $\left.3 \mathrm{H},{ }^{3} \mathrm{~J}_{\mathrm{HH}}=8.0 \mathrm{~Hz}, \mathrm{H}_{\text {fluorenyl, }} \mathrm{H}_{4}\right), 8.17$ (m, $5 \mathrm{H}, 2 \mathrm{H}_{\text {phenyl }}$ and $\left.3 \mathrm{H}_{\text {fluorenyl: }} \mathrm{H}_{3}\right), 8.05\left(\mathrm{~d}, 3 \mathrm{H},{ }^{3} \mathrm{~J}_{\mathrm{HH}}=7.2 \mathrm{~Hz}, \mathrm{H}_{\text {fluorenyl, }} \mathrm{H}_{5}\right), 7.89\left(\mathrm{~d}, 2 \mathrm{H},{ }^{3} \mathrm{~J}_{\mathrm{HH}}=\right.$ $\left.8.0 \mathrm{~Hz}, \mathrm{H}_{\text {phenyl }}\right), 7.69$ (d, 3H, $\left.{ }^{3} \mathrm{~J}_{\mathrm{HH}}=7.6 \mathrm{~Hz}, \mathrm{H}_{\text {fluorenyl, }} \mathrm{H}_{8}\right), 7.53$ (m, 3H, $\left.\mathrm{H}_{\text {fluorenyl }}, \mathrm{H}_{6}\right), 7.44$ (m, $3 \mathrm{H}, \mathrm{H}_{\text {fluorenyl }}, \mathrm{H}_{7}$ ), 4.20 (s, 6H, 3CH $\mathrm{CH}_{2 \text {-fluorenyl }}$ ), 3.30 (s, 1H, $\mathrm{C}_{\text {alkyne-H) }}$. FT-IR (n, KBr, cm ${ }^{-1}$ ) : $2106(\mathrm{C} \equiv \mathrm{C}) . \mathbf{U V}$-vis $\left(\lambda \max ,\left(\varepsilon, 10^{-3} \mathrm{M}^{-1} \cdot \mathrm{cm}^{-1}\right), \mathrm{CH}_{2} \mathrm{Cl}_{2}, \mathrm{~nm}\right): 273$ (36), 303 (19), 428 (316), 554 (11), 596 (3). Analysis : calcd for $\mathrm{C}_{67} \mathrm{H}_{40} \mathrm{~N}_{4} \mathrm{Zn} \mathrm{CH}_{3} \mathrm{OH}: \mathrm{C}, 81.80, \mathrm{H}, 4.44, \mathrm{~N}, 5.61$, found C, 81.22, H, 4.75, N, 5.18. MALDI-TOF MS : calcd for $\mathrm{C}_{67} \mathrm{H}_{40} \mathrm{~N}_{4} \mathrm{Zn}: 965.25444[\mathrm{MH}]^{+}$, found : $965.90810[\mathrm{MH}]^{+}$. MS (ESI) : calcd for $\mathrm{C}_{67} \mathrm{H}_{40} \mathrm{~N}_{4} \mathrm{Zn}: 987.24421[\mathrm{MNa}]^{+}$, found : $987.2432[\mathrm{MNa}]^{+}$.

4.2.5. Synthesis of 5,10,15-(trifluorenyl)-20-(4-iodophenyl)porphyrin $\mathbf{1 3}$ - A solution of 4-iodobenzaldehyde (1.00 g, $4.3 \mathrm{mmol})$, 2-fluorenecarboxaldehyde (2.52 g, $12.9 \mathrm{mmol}$ ) and pyrrole $(1.18 \mathrm{~mL}, 17.2 \mathrm{mmol})$ in distilled chloroform $(1.5 \mathrm{~L})$ was placed in a two necked flask under argon. The chloroform solution was degassed by argon bubbling for 20 minutes. The flask was covered with aluminium foil since the reaction is light sensitive at this stage. Boron trifluoride diethyl etherate, $\mathrm{BF}_{3} . \mathrm{OEt}_{2}(690 \mu \mathrm{L})$ was added with a syringe. The solution was stirred for three hours at room temperature. Then, the oxidant, $p$-chloranil $(3.44 \mathrm{~g}, 14$ mmol) was added, and the reaction mixture was refluxed for one hour (light protection was removed). After neutralization of the acid catalyst by adding two pipettes of triethylamine, the solvent was removed. The resulting black solid was purified by two column chromatographies (column 1: $\mathrm{CH}_{2} \mathrm{Cl}_{2} /$ heptane $1: 1$, and then column $2: \mathrm{CH}_{2} \mathrm{Cl}_{2} /$ heptane $1: 4$ ) affording $330 \mathrm{mg}$ $(8 \%)$ of the desired porphyrin $\mathbf{1 3}$ as a purple solid. The new intermediate porphyrin $\mathbf{1 3}$ was fully characterized; the hydrogen and carbon atom-labeling scheme for this monomer is shown in Figure 2. ${ }^{1} \mathbf{H}$ NMR $\left(400 \mathrm{MHz}, \mathrm{CDCl}_{3}, \delta\right.$ in ppm) : $8.94\left(\mathrm{~d}, 2 \mathrm{H},{ }^{3} \mathrm{~J}_{\mathrm{HH}}=5.0 \mathrm{~Hz}, \mathrm{H}_{\beta}\right.$ pyrrolic), 8.92 (s, 4H, $\mathrm{H}_{\beta \text {-pyrrolic }}$ ), 8.84 (d, 2H, ${ }^{3} \mathrm{~J}_{\mathrm{HH}}=4.4 \mathrm{~Hz}, \mathrm{H}_{\beta \text {-pyrrolic }}$ ), 8.39 (s, 3H, $\mathrm{H}_{\text {fluorenyl, }} \mathrm{H}_{1}$ ), $8.24\left(\mathrm{~d}, 3 \mathrm{H},{ }^{3} \mathrm{~J}_{\mathrm{HH}}=8.0 \mathrm{~Hz}, \mathrm{H}_{\text {fluorenyl, }} \mathrm{H}_{4}\right), 8.15\left(\mathrm{~m}, 5 \mathrm{H}, 2 \mathrm{H}_{\text {phenyl }}, \mathrm{H}_{\mathrm{A}}\right.$ and $\left.3 \mathrm{H}_{\text {fluorenyl, }} \mathrm{H}_{3}\right), 8.05(\mathrm{~d}$, $\left.3 \mathrm{H},{ }^{3} \mathrm{~J}_{\mathrm{HH}}=7.6 \mathrm{~Hz}, \mathrm{H}_{\text {fluorenyl, }} \mathrm{H}_{5}\right), 7.96\left(\mathrm{~d}, 2 \mathrm{H},{ }^{3} \mathrm{~J}_{\mathrm{HH}}=7.6 \mathrm{~Hz}, \mathrm{H}_{\text {phenyl }}, \mathrm{H}_{\mathrm{B}}\right), 7.70\left(\mathrm{~d}, 3 \mathrm{H},{ }^{3} \mathrm{~J}_{\mathrm{HH}}=\right.$ $\left.7.2 \mathrm{~Hz}, \mathrm{H}_{\text {fluorenyl }}, \mathrm{H}_{8}\right), 7.52$ (m, 3H, $\left.\mathrm{H}_{\text {fluorenyl, }} \mathrm{H}_{6}\right), 7.44$ (m, 3H, $\left.\mathrm{H}_{\text {fluorenyl }}, \mathrm{H}_{7}\right), 4.20$ (s, 6H, 3CH fluorenyl), - 2.60 (s, 2H, NH). Rf on silica plate using DCM/heptane $(60: 40): 0.48$. UV-vis ( $\lambda$ max, $\left.\left(\varepsilon, 10^{-3} \mathrm{M}^{-1} \cdot \mathrm{cm}^{-1}\right), \mathrm{CH}_{2} \mathrm{Cl}_{2}, \mathrm{~nm}\right): 275$ (34), 424 (287), 519 (11), 556 (5), 593 (1.5), 649 (1.6). Analysis : calcd for $\mathrm{C}_{65} \mathrm{H}_{41} \mathrm{IN}_{4} 0.5 \mathrm{CH}_{2} \mathrm{Cl}_{2}: \mathrm{C}, 75.11, \mathrm{H}, 4.04, \mathrm{~N}, 5.35$, found : C, 74.60, 
$\mathrm{H}, 4.40, \mathrm{~N}$, 5.17. MALDI-TOF MS : calcd for $\mathrm{C}_{65} \mathrm{H}_{41} \mathrm{IN}_{4}: 1027.22737[\mathrm{MNa}]^{+}$, found 1027.22640 $[\mathrm{MNa}]^{+}$and 1005.24542 $[\mathrm{MH}]^{+}$, found 1005.24460 [MH] $]^{+}$

\subsection{Synthesis of dimers 7 and 8}

4.3.1. Synthesis of dimer 7 using $\mathrm{AsPh}_{3}$ as a catalytical ligand - A solution of $\mathbf{1 2}$, zinc(II)-5,10,15-(trifluorenyl)-20-(4-ethynylphenyl)porphyrinato (52 $\mathrm{mg}, 0.053 \mathrm{mmol}$ ), free base 13, 5,10,15-(trifluorenyl)-20-(4-iodophenyl)porphyrin $\quad(50 \mathrm{mg}, \quad 0.050 \mathrm{mmol})$, $\mathrm{Pd}_{2}(\mathrm{dba})_{3} \cdot \mathrm{CHCl}_{3}(16 \mathrm{mg}, 0.015 \mathrm{mmol})$, and $\mathrm{AsPh}_{3}(37 \mathrm{mg}, 0.12 \mathrm{mmol})$ was prepared in 18 $\mathrm{mL}$ of freshly distilled THF under argon. Then, triethylamine $(3.5 \mathrm{~mL})$ was added to this solution. This reaction mixture was stirred for 72 hours at $35^{\circ} \mathrm{C}$ under argon. Then, it was cooled at room temperature, filtered and evaporated to dryness. The residue was purified by column chromatography on silica gel using DCM/heptane $(1: 1)$ as eluent then increasing the proportion of DCM till $100 \%$ affording the product $\mathbf{7}$, as a dark red impure powder with a yield of around 5\%. Two side products; 14 and $\mathbf{1 5}$ were isolated and characterized as shown below (see part 4.4.).

4.3.2. Synthesis of dimer 7 using $P(o-t o l)_{3}$ as a catalytical ligand - A solution of one equivalent of 12, zinc(II)-5,10,15-(trifluorenyl)-20-(4-ethynylphenyl)porphyrinato (48 mg, $0.05 \mathrm{mmol}$ ), one equivalent of free base 13, 5,10,15-(trifluorenyl)-20-(4iodophenyl)porphyrin $(50 \mathrm{mg}, 0.05 \mathrm{mmol}), \mathrm{Pd}_{2}(\mathrm{dba})_{3} . \mathrm{CHCl}_{3}(7.8 \mathrm{mg}, 0.007 \mathrm{mmol})$, and $\mathrm{P}(\mathrm{o}-$ tol $)_{3}(18 \mathrm{mg}, 0.06 \mathrm{mmol})$ in $18 \mathrm{~mL}$ of freshly distilled toluene was prepared under argon. Finally, triethylamine $(3.5 \mathrm{~mL})$ was added to this solution. The reaction mixture was stirred for 24 hours at $35^{\circ} \mathrm{C}$ under argon. Then, it was cooled at room temperature, filtered and evaporated to dryness. The residue was purified twice by column chromatography on silica gel using DCM/heptane $(1: 1)$ as eluent then increasing the proportion of DCM. Product 7 was isolated as a dark red powder when DCM/heptane $(3: 1)$ were used. Then, the obtained product was precipitated in heptane to afford 7 as a pure product with $25 \%$ yield. The reaction was followed by MALDI-TOF MS as well as by NMR. This new compound 7 is very soluble in most organic solvents and can be purified by precipitation (DCM/heptane). Compound 7 behaved well on silica gel chromatography and was fully characterized by usual solution spectroscopies (NMR, mass spectrometry) and microanalysis; the hydrogen and carbon atomlabeling scheme for this monomer is shown in Figure 3. ${ }^{\mathbf{1}} \mathbf{H} \mathbf{N M R}\left(500 \mathrm{MHz}, \mathrm{CDCl}_{3}, \delta\right.$ in

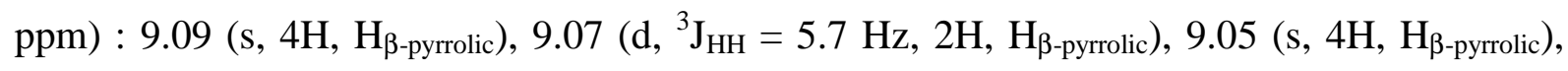


9.04 (s, 4H, $\mathrm{H}_{\beta \text {-pyrrolic }}$ ), 9.02 (d, ${ }^{3} \mathrm{~J}_{\mathrm{HH}}=5.6 \mathrm{~Hz}, 2 \mathrm{H}, \mathrm{H}_{\beta \text {-pyrrolic }}$ ), 8.42 (s, 6H, $\mathrm{H}_{\text {fluorenyl }}, \mathrm{H}_{1}$ ) $), 8.35$ (m, 2H, $\left.\mathrm{H}_{\text {phenyl }}\right), 8.29$ (m, 6H, $\left.\mathrm{H}_{\text {fluorenyl }}, \mathrm{H}_{4}{ }^{\prime}\right), 8.26$ (m, $\left.2 \mathrm{H}, \mathrm{H}_{\text {phenyl }}\right), 8.18$ (m, 6H, $\mathrm{H}_{\text {fluorenyl }}, \mathrm{H}_{3^{\prime}}$ ), $8.06\left(\mathrm{~d}, 6 \mathrm{H},{ }^{3} \mathrm{~J}_{\mathrm{HH}}=7.8 \mathrm{~Hz}, \mathrm{H}_{\text {fluorenyl }}, \mathrm{H}_{5}\right.$ ) $), 8.05\left(\mathrm{~m}, 2 \mathrm{H}, \mathrm{H}_{\text {phenyl }}\right), 7.71\left(\mathrm{~d}, 6 \mathrm{H},{ }^{3} \mathrm{~J}_{\mathrm{HH}}=7.6 \mathrm{~Hz}\right.$, $\left.\mathrm{H}_{\text {fluorenyl }}, \mathrm{H}_{8^{\prime}}\right), 7.54\left(\mathrm{t}, 6 \mathrm{H},{ }^{3} \mathrm{~J}_{\mathrm{HH}}=6.9 \mathrm{~Hz}, \mathrm{H}_{\text {fluorenyl }}, \mathrm{H}_{6}\right.$ ) $), 7.43\left(\mathrm{t}, 6 \mathrm{H},{ }^{3} \mathrm{~J}_{\mathrm{HH}}=6.5 \mathrm{~Hz}, \mathrm{H}_{\text {fluorenyl }}\right.$, $\left.\mathrm{H}_{7^{\prime}}\right), 7.42\left(\mathrm{~m}, 2 \mathrm{H}, \mathrm{H}_{\text {phenyl }}\right), 4.22\left(\mathrm{~s}, 12 \mathrm{H}, 6 \mathrm{CH}_{2 \text {-fluorenyl }}\right){ }^{13} \mathbf{C} \mathbf{~ N M R}\left(\mathrm{CDCl}_{3}\right): 150.4\left(\mathrm{~m}, \mathrm{C}_{\mathrm{q}}, \mathrm{C}_{1-}\right.$ 4-6-9-11-14-16-19), $143.7\left(\mathrm{C}_{\mathrm{q}}, \mathrm{C}_{9}{ }^{\prime}\right), 141.7\left(\mathrm{C}_{\mathrm{q}}, \mathrm{C}_{4}{ }^{\prime}\right), 141.6\left(\mathrm{C}_{\mathrm{q}}, \mathrm{C}_{8}{ }^{\prime}\right), 141.5\left(\mathrm{C}_{\mathrm{q}}, \mathrm{C}_{5}{ }^{\prime}\right), 134.7\left(\mathrm{C}_{\mathrm{B}}\right)$,

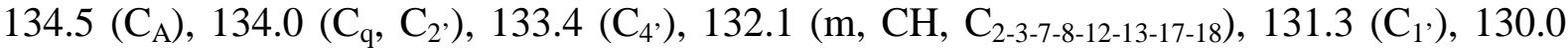
$\left(\mathrm{C}_{\mathrm{B}}\right), 127.0\left(\mathrm{C}_{6}\right.$, and $\left.\mathrm{C}_{7}\right), 126.8\left(\mathrm{C}_{\mathrm{A}^{\prime}}\right), 125.2\left(\mathrm{C}_{8^{\prime}}\right), 121.6\left(\mathrm{~m}, \mathrm{C}_{\mathrm{q}}, \mathrm{C}_{5-10-15-20}\right), 120.2\left(\mathrm{C}_{5},\right), 117.8$ $\left(\mathrm{C}_{3},\right), 37.1\left(\mathrm{C}_{9}\right)$. Rf on silica plate using DCM/heptane $(60: 40): 0.36$. UV-vis $\left(\lambda \max ,\left(\varepsilon, 10^{-}\right.\right.$ $\left.\left.{ }^{3} \mathrm{M}^{-1} \cdot \mathrm{cm}^{-1}\right), \mathrm{CH}_{2} \mathrm{Cl}_{2}, \mathrm{~nm}\right)$ : 281 (150), 428 (479), 513 (10), 555 (37), 597 (16), 643 (w). Analysis : calcd for $\mathrm{C}_{132} \mathrm{H}_{80} \mathrm{~N}_{8} \mathrm{Zn} \cdot 3 \mathrm{CH}_{2} \mathrm{Cl}_{2}: \mathrm{C}, 77.27, \mathrm{H}, 4.13, \mathrm{~N}, 5.34$, found : C, 77.31, H, 4.82, N, 5.02. MALDI-TOF MS : calcd for $\mathrm{C}_{132} \mathrm{H}_{80} \mathrm{~N}_{8} \mathrm{Zn}: 1841.57974[\mathrm{MH}]^{+}$, found $1841.18810[\mathrm{MH}]^{+}$.

4.3.3. Synthesis of free dimer $\mathbf{8}$ - This new dimer $\mathbf{8}$ was obtained from the mono zinc complex 7 by acidic treatments. To a solution of one equivalent of dimer 7 (10 mg, 0.005 $\mathrm{mmol}$ ), in $5 \mathrm{~mL}$ of freshly distilled DCM under argon, was added trifluoroacetic acid in large excess (TFA, $0.05 \mathrm{~mL}, 75 \mathrm{mg}, 0.66 \mathrm{mmol}$ ). Immediately, the dark red DCM solution turned green. The reaction mixture was stirred for 30 minutes at room temperature and was controlled by UV-Visible spectrometry to be sure that zinc was entirely eliminated from the porphyrin macrocycle, to obtain the totally free and protonated porphyrin dimer. Finally, potassium carbonate was added to neutralize this dark green solution, to obtain the free, but non protonated porphyrin dimer 8. The red solution was stirred for 30 minutes at room temperature. Then, the residue was filtrated on silica gel using DCM as eluent to afford neutral 8, as a pure product : a dark red powder with $95 \%$ yield. ${ }^{1} \mathbf{H} \mathbf{~ N M R}\left(500 \mathrm{MHz}, \mathrm{CDCl}_{3}\right.$ $\delta$ in ppm) : $8.94\left(\mathrm{~m}, 16 \mathrm{H}, \mathrm{H}_{\beta \text {-pyrrolic }}\right), 8.62\left(\mathrm{~m}, 4 \mathrm{H}, \mathrm{H}_{\text {phenyl }}\right), 8.32\left(\mathrm{~s}, 6 \mathrm{H}, \mathrm{H}_{\text {fluorenyl }}, \mathrm{H}_{1}\right), 8.18$ (m, $\left.6 \mathrm{H}, \mathrm{H}_{\text {fluorenyl }}, \mathrm{H}_{4}\right), 8.08\left(\mathrm{~m}, 6 \mathrm{H}, \mathrm{H}_{\text {fluorenyl }}, \mathrm{H}_{3}\right), 7.98\left(\mathrm{~d}, 6 \mathrm{H},{ }^{3} \mathrm{~J}_{\mathrm{HH}}=7.8 \mathrm{~Hz}, \mathrm{H}_{\text {fluorenyl }}, \mathrm{H}_{5}\right), 7.78$ $\left(\mathrm{m}, 4 \mathrm{H}, \mathrm{H}_{\text {phenyl }}\right), 7.68\left(\mathrm{~d}, 6 \mathrm{H},{ }^{3} \mathrm{~J}_{\mathrm{HH}}=7.6 \mathrm{~Hz}, \mathrm{H}_{\text {fluorenyl }}, \mathrm{H}_{8}\right), 7.52\left(\mathrm{t}, 6 \mathrm{H},{ }^{3} \mathrm{~J}_{\mathrm{HH}}=6.9 \mathrm{~Hz}, \mathrm{H}_{\text {fluorenyl }}\right.$, $\left.\mathrm{H}_{6}\right), 7.43\left(\mathrm{t}, 6 \mathrm{H},{ }^{3} \mathrm{~J}_{\mathrm{HH}}=6.5 \mathrm{~Hz}, \mathrm{H}_{\text {fluorenyl }}, \mathrm{H}_{7}\right), 4.22\left(\mathrm{~s}, 12 \mathrm{H}, 6 \mathrm{CH}_{2 \text {-fluorenyl }}\right),-2.70(4 \mathrm{H}, \mathrm{NH})$.

UV-vis $\left(\lambda \max ,\left(\varepsilon, 10^{-3} \mathrm{M}^{-1} \cdot \mathrm{cm}^{-1}\right), \mathrm{CH}_{2} \mathrm{Cl}_{2}, \mathrm{~nm}\right)$ : Compound 8 as a tetra cation $\left[\mathbf{H}_{4}\right.$ Por-

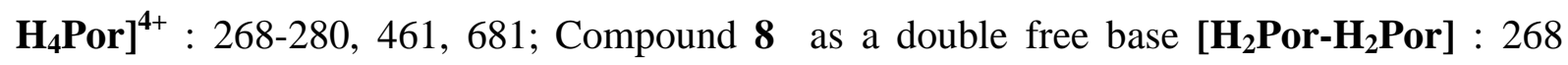
(181), 426 (522), 521 (26), 557 (15), 595 (5), 650 (4). MALDI-TOF MS : calcd for $\mathrm{C}_{132} \mathrm{H}_{82} \mathrm{~N}_{8}: 1779.66624[\mathrm{MH}]^{+}$, found $1778.95120[\mathrm{MH}]^{+}$. 


\subsection{Caracterisation of by products 14 and 15}

4.4.1. Complex Zn(II)-5,10,15-(trifluorenyl)-20-(4-phenylethynylphenyl)porphyrinato 14 - The porphyrin 14 was obtained pure as a first fraction of the column when using DCM/heptane $(1: 1)$. This by-product 14 was isolated as a purple solid and characterized by proton NMR and Mass. ${ }^{1} \mathbf{H}$ NMR $\left(400 \mathrm{MHz}, \mathrm{CDCl}_{3}, \delta\right.$ in ppm) : $9.01\left(\mathrm{~d}, 2 \mathrm{H},{ }^{3} \mathrm{~J}_{\mathrm{HH}}=4.8 \mathrm{~Hz}\right.$, $\mathrm{H}_{\beta \text {-pyrrolic }}$ ), 9.00 (s, 4H, $\mathrm{H}_{\beta \text {-pyrrolic }}$ ), 8.95 (d, $2 \mathrm{H},{ }^{3} \mathrm{~J}_{\mathrm{HH}}=4.8 \mathrm{~Hz}, \mathrm{H}_{\beta \text {-pyrrolic }}$ ), 8.38 (s, 3H, $\mathrm{H}_{\text {fluorenyl, }}$ $\left.\mathrm{H}_{1}\right), 8.22\left(\mathrm{~m}, 5 \mathrm{H}, 2 \mathrm{H}_{\text {phenyl }}\right.$ and $\left.3 \mathrm{H}_{\text {fluorenyl }}, \mathrm{H}_{4}\right), 8.14-8.11\left(\mathrm{~m}, 3 \mathrm{H}, \mathrm{H}_{\text {fluorenyl, }} \mathrm{H}_{3}\right), 8.05-8.02(\mathrm{~m}$, $\left.3 \mathrm{H}, \mathrm{H}_{\text {fluorenyl, }} \mathrm{H}_{5}\right), 7.92\left(\mathrm{~d}, 2 \mathrm{H},{ }^{3} \mathrm{~J}_{\mathrm{HH}}=8.0 \mathrm{~Hz}, \mathrm{H}_{\text {phenyl }}\right), 7.69-7.66\left(\mathrm{~m}, 5 \mathrm{H}, 2 \mathrm{H}_{\text {phenyl }}\right.$ and $3 \mathrm{H}_{\text {fluorenyl, }}$

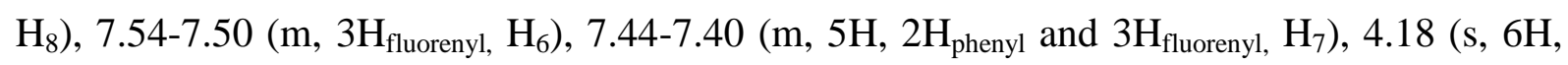

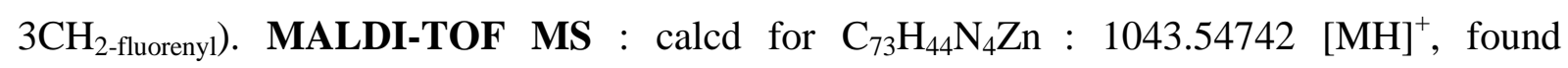
$1043.0360[\mathrm{MH}]^{+}$.

4.4.2. Compound 5,10,15-(trifluorenyl)-20-(4-phenyl-(diphenyl-Arsine))porphyrin 15 Among the obtained fractions from the column chromatography, the arsine porphyrin $\mathbf{1 5}$ was obtained in a purple solid, always mixed with non-reacted iodo compound $\mathbf{1 3}$ or dimer $\mathbf{7}$. This by-product 15 was characterized by Mass: MALDI-TOF MS : calcd for $\mathrm{C}_{77} \mathrm{H}_{51} \mathrm{AsN}_{4}$ : 1108.17740 [MH] $]^{+}$; found $1108.04600[\mathrm{MH}]^{+}$.

\section{Acknowledgements}

The authors are grateful to Dr. S. Sinbandhit (CRMPO) for the technical assistance and helpful discussions for NMR. The authors are grateful to Region Bretagne for ARED grant for A. Merhi, MRT for PhD grant concerning S. Drouet. Partial Funding for the project was obtained from the "Université Européenne de Bretagne" (UEB) and from FEDER by an EPT grant in the "MITTSI" program from RTR BRESMAT.

\section{References}

(1) Wasielewski, M. R. J. Org. Chem. 2006, 71, 5051.

(2) McDermott, G.; Prince, S. M.; Freer, A. A.; Hawthornthwaitelawless, A. M.; Papiz, M. Z.; Cogdell, R. J.; Isaacs, N. W. Nature 1995, 374, 517.

(3) Anton, J. A.; Kwong, J.; Loach, P. A. J. Heterocycl. Chem. 1976, 13, 717.

(4) Milgrom, L. R. J. Chem. Soc., Perkin Trans. 1. 1983. 
(5) Khoury, R. G.; Jaquinod, L.; Smith, K. M. J. Chem. Soc., Chem. Commun., 1997, 1057.

(6) Lin, V. S.-Y.; Di Magno, S. G.; Therien, J. M. Science 1994, 264, 1105.

(7) Lin, V. S.-Y.; Therien, J. M. Chem. Eur. J. 1995, 1, 645.

(8) Lindsey, J. S.; Prathapan, S.; Johnson, T. E.; Wagner, R. W. Tetrahedron 1994, $50,8941$.

(9) Wagner, R. W.; Johnson, T. E.; Li, F.; Lindsey, J. S. J. Org. Chem. 1995, 60, 5266.

(10) Paul-Roth, C.; Rault-Berthelot, J.; Simonneaux, G. Tetrahedron 2004, 60, 12169.

(11) Poriel, C.; Ferrand, Y.; Le Maux, P.; Paul-Roth, C.; Simonneaux, G.; Rault-Berthelot, J. J. Electroanal. Chem. 2005, 583, 92.

(12) Paul-Roth, C. O.; Simonneaux, G. Tetrahedron Lett. 2006, 47, 3275.

(13) Paul-Roth, C. O.; Simonneaux , G. C.R. Acad. Sci., Ser. IIb: Chim. 2006, 9, 1277.

(14) Paul-Roth, C.; Williams, G.; Letessier, J.; Simonneaux , G. Tetrahedron Lett. 2007, $48,4317$.

(15) Drouet, S.; Paul-Roth, C. O.; Fattori, V.; Cocchi, M.; Williams, J. A. G. New J. Chem. 2011, 35, 438.

(16) Ren, X.; Ren, A.; Feng, J.; Sun, C. Journal of Photochem. and Photobiol. A: Chemistry 2009, 203, 92.

(17) Drouet, S.; Merhi, A.; Argouarch, G.; Paul, F.; Mongin, O.; Blanchard-Desce, M.; Paul-Roth, C. O. Tetrahedron 2012, 68, 98.

(18) Merhi, A.; Drouet, S.; Kerisit, N.; Paul-Roth, C. O. Tetrahedron 2012, 68, 7901.

(19) Paul-Roth, C.; Rault-Berthelot, J.; Simonneaux, G.; Poriel, C.; Abdalilah, M.; Letessier, J. J. Electroanal. Chem. 2006, 597, 19.

(20) Drouet, S.; Paul-Roth, C.; Simonneaux, G. Tetrahedron 2009, 65, 2975.

(21) Drouet, S.; Paul-Roth, C. O. Tetrahedron 2009, 65, 10693.

(22) Li, B.; Li, J.; Fu, Y.; Bo, Z. J. Am. Chem. Soc. 2004, 126, 3430.

(23) Austin, W. B.; Bilow, N.; Kelleghan, W. J.; Lau, K. S. Y. J. Org. Chem. 1981, 46, 2280.

(24) Gouterman, M. The porphyrins, Academic press, New-York, 1978, vol. 3, 24.

(25) Gouterman, M. J. Mol. Spectrosc. 1961, 6, 138.

(26) Austin, E.; Gouterman, M. Bioinorg. Chem. 1978, 9, 281.

(27) Falk, J. E. Porphyrins and Metalloporphyrins, Elsevier, Amsterdam, 1964.

(28) Drouet, S.; Ballut, S.; Rault-Berthelot, J.; Turban, P.; Paul-Roth, C. Thin Solid Films 2009, 517, 5474.

(29) Owens, J. W.; Smith, R.; Robinson, R.; Robins, M. Inorg. Chim. Acta 1998, 279, 226.

(30) Zang, X. H.; Xie, Z. Y.; Wu, F. P.; Zhou, L. L.; Wong, O. Y.; Lee, C. S.; Kwong, H. L.; Lee, S. T.; Wu, S. K. Chem. Phys. Lett. 2003, 382, 561.

(31) Quimby, D. J.; Longo, F. R. J. Am. Chem. Soc. 1975, 97, 5111.

(32) Demas, J. N.; Crosby, G. A. J. Phys. Chem. 1971, 75, 991. 